\title{
Secuencia de ocupación y desarrollo constructivo del asentamiento de Caramoro I (Elche, Alicante): aportaciones a la arquitectura argárica*
}

\author{
Occupation sequence and building development in the settlement \\ of Caramoro I (Elche, Alicante): contributions to Argaric architecture
}

Francisco Javier Jover Maestre ${ }^{1}$

Instituto Universitario de Investigación en Arqueología y Patrimonio Histórico (INAPH). Universidad de Alicante

María Pastor Quiles²

Departamento de Prehistoria, Arqueología, Historia Antigua, Filología Griega y Filología Latina. Universidad de Alicante

Ricardo E. Basso Rial ${ }^{3}$

Instituto Universitario de Investigación en Arqueología y Patrimonio Histórico (INAPH). Universidad de Alicante

Sergio Martínez Monleón ${ }^{4}$

Departamento de Prehistoria, Arqueología, Historia Antigua, Filología Griega y Filología Latina. Universidad de Alicante

Juan Antonio López Padilla 5

Museo Arqueológico Provincial de Alicante (MARQ)

\begin{abstract}
RESUMEN
A pesar de que la cultura de El Argar es una de las entidades arqueológicas mejor conocidas del ámbito peninsular, no son muchos los trabajos efectuados sobre los aspectos arquitectónicos y del desarrollo constructivo de los asentamientos argáricos excavados. En este artículo se presentan las formas arquitectónicas, las técnicas y materiales constructivos empleados y la secuencia de ocupación del asentamiento de Caramoro I (Elche, Alicante) a partir del análisis estratigráfico y de estructuras conservadas, reforzada y avalada con una serie de dataciones absolutas sobre muestras de vida corta. Los resultados obtenidos han mostrado que Caramoro I fue un asentamiento de carácter agropecuario, ubicado en los límites fronterizos septentrionales de El Argar, que fue reformado con la intención de mejorar su protección y defensa, a partir de la fortificación de su zona de acceso. Sus concomitancias con otros asentamientos similares en territorios de frontera más orientales vienen a mostrar su carácter logístico.
\end{abstract}

Palabras clave: Edad del Bronce; El Argar; edificación; fortificaciones; técnicas constructivas; materiales.

\begin{abstract}
Although El Argar culture is one of the best-known archaeological entities in the Iberian Peninsula, there are not many works published on the architectural aspects and constructive development of the Argaric settlements which have been excavated. This article presents the architectural forms, construction techniques and materials and the occupation sequence of the settlement of Caramoro I (Elche, Alicante), based on the stratigraphic analysis and preserved structures, reinforced with a series of absolute dates on short life samples. The results obtained have shown that Caramoro I was a settlement of agricultural orientation, located in the northern borders of the El Argar territory, reformed to improve its protection and defense, with the fortification of its access. Its similarities with other settlements in the Eastern border territories show the logistical function of Caramoro I.
\end{abstract}

Key words: Bronze Age; El Argar; construction; fortifications; techniques; materials.

\footnotetext{
" El presente trabajo ha sido realizado en el marco del proyecto de investigación "Espacios sociales y espacios de frontera durante el Calcolítico y la Edad del Bronce en el Levante de la península ibérica" (HAR2016-76586-P), financiado por el Ministerio de Economía y Competitividad del Gobierno de España. javier.jover@ua.es / ORCID iD: https://orcid.org/0000-0001-5213-2361

m.pastor@ua.es / ORCID iD: https://orcid.org/0000-0001-6112-6422

ricardo.basso@ua.es / ORCID iD: https://orcid.org/0000-0002-5323-2281

4 sergio.mmonleon@ua.es / ORCID iD: https://orcid.org/0000-0002-6352-4499

5 japadi@diputacionalicante.es / ORCID iD: https://orcid.org/0000-0002-1506-4731
} 
Recibido: 21-02-2019. Aceptado: 06-05-2019. Publicado online: 28-08-2019

\section{Cómo citar este artículo / Citation}

Jover Maestre, F. J., Pastor Quiles, M., Basso Rial, R. E., Martínez Monleón, S. y López Padilla, J. A. 2019: "Secuencia de ocupación y desarrollo constructivo del asentamiento de Caramoro I (Elche, Alicante): aportaciones a la arquitectura argárica", Arqueología de la Arquitectura, 16 : e083. https://doi.org/10.3989/arq.arqt.2019.005

Copyright: (c) 2019 Consejo Superior de Investigaciones Científicas (CSIC) - Universidad del País Vasco/Euskal Herriko Unibertsitatea (UPV/EHU). Este es un artículo de acceso abierto distribuido bajo los términos de la licencia de uso y distribución Creative Commons Reconocimiento 4.0 Internacional (CC BY 4.0).

\section{INTRODUCCIÓN}

Entre los estudios prehistóricos en la península ibérica destacan, sobremanera, los efectuados sobre El Argar (Siret y Siret 1890; Lull 1983; Aranda et al. 2015). La larga tradición investigadora en el sureste ha permitido conocer en profundidad numerosos aspectos de la materialidad y del desarrollo de esta cultura arqueológica, hasta el punto de que, en la actualidad, es una de entidades culturales para la que más propuestas de orden sociológico han sido formuladas.

Todo ello ha sido posible gracias a la intervención arqueológica en un buen número de asentamientos, en especial, durante las últimas décadas, generando una amplia base empírica y cronológica. Sin embargo, solamente unos pocos enclaves argáricos han sido excavados prácticamente en su totalidad, como Peñalosa, Castellón Alto o, más recientemente, Tira del Lienzo y La Almoloya. En este sentido, son muy pocos los estudios específicos publicados sobre la arquitectura argárica, la secuencia de ocupación asociada al desarrollo constructivo de los asentamientos, o los materiales y técnicas empleados en su edificación.

Por ello, el objetivo del presente trabajo es el de contribuir a los estudios sobre la arquitectura argárica, presentando el caso del pequeño asentamiento de Caramoro I. Y es que, aunque sus dimensiones son reducidas, la inversión laboral efectuada en su planificación urbanística y en su construcción fue de considerable magnitud. Además, la posibilidad de realizar una lectura estratigráfica de las estructuras conservadas, a pesar de haber sido excavado en la década de 1980 e inicios de los 1990, apoyada por una serie de dataciones radiocarbónicas, ha permitido establecer cronológicamente su secuencia de ocupación y desarrollo constructivo, contribuyendo a fijar con precisión la duración de este tipo de asentamientos fortificados de pequeño tamaño dentro del desarrollo temporal de la cultura argárica.

\section{CARAMORO I: EMPLAZAMIENTO Y CARACTERÍSTICAS}

Caramoro I se localiza sobre un pequeño espolón rocoso en el inicio de la sierra de Borbano, extremo septentrional del paraje conocido como Aigua Dolça i Salà, dentro del término municipal de Elche (Alicante) (Fig. 1). Las coordenadas centrales del área ocupada por el yacimiento son X: $700.662 \mathrm{~m}$; Y: 4.240.791 m (Datum ETRS89; Huso 30), con una altura sobre el nivel del mar de $138 \mathrm{~m}$. Se eleva unos $48 \mathrm{~m}$ sobre el entorno del fondo del valle, disponiéndose en voladizo sobre el cauce del río Vinalopó, del que dista $170 \mathrm{~m}$. Encajado entre dos barrancos, configura un auténtico balcón sobre el glacis descendiente y el cauce del río Vinalopó, desde donde se puede divisar un amplio trecho del campo de Elche y ejercer un control directo sobre su principal vía de comunicación.

Desde el escarpe rocoso donde se ubica, en la margen izquierda del río Vinalopó, se cuenta con un amplio control visual hacia las tierras llanas orientales y meridionales, alcanzando a cubrir el marjal de Crevillente-Elche y parte de la bahía de Santa Pola. Ajeno

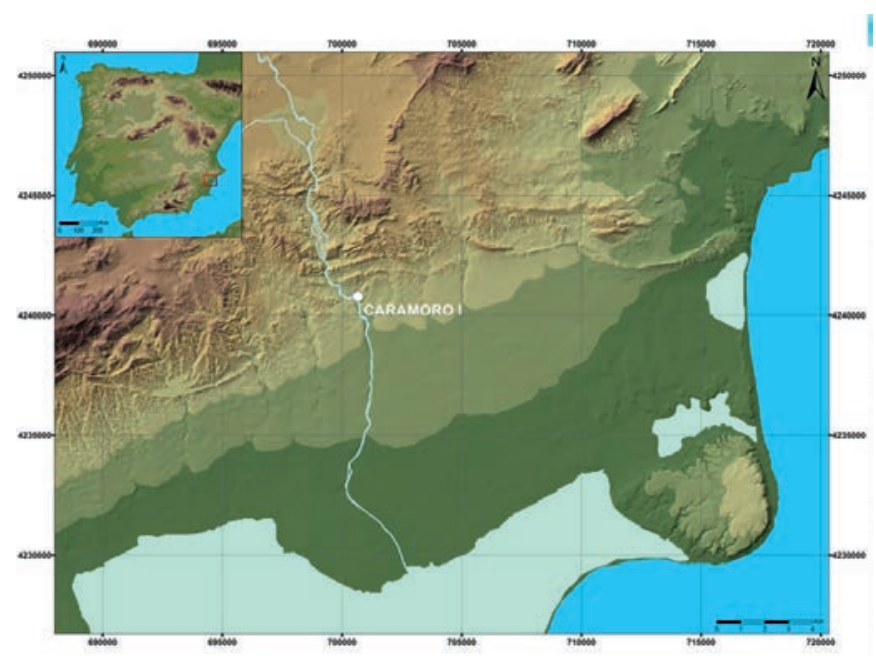

Figura 1. Ubicación del yacimiento de Caramoro I. 
al comportamiento de intervisibilidad que manifiestan la mayoría de los asentamientos argáricos de la zona, Caramoro I se enmarca dentro de un grupo de asentamientos de muy pequeño tamaño, en este caso no supera los $796 \mathrm{~m}^{2}$, y escasa altitud relativa. Solamente guarda una relación visual directa con el próximo yacimiento de La Moleta, a pesar de que en sus proximidades se encuentran otros yacimientos como los de la Serra del Búho, Tabayá o el Barranco de los Arcos (Martínez Monleón 2014).

Por último, cabe indicar que Caramoro I está directamente edificado sobre un conjunto estratificado de materiales pliocenos, básicamente calizas y conglomerados. El agua, debido a su alta porosidad y permeabilidad, se filtra con suma rapidez. Debajo de tales conglomerados aparece un nivel de margas arcillosas triásicas de coloración ocre-blanquecina. Geomorfológicamente estos dos niveles dan un relieve típico de murallones con bruscas pendientes (Fig. 2), debido a que la erosión se realiza en las margas infrayacentes, lo que produce una caída por gravedad de parte del nivel superior de conglomerados (Pignatelli 1973).

El espolón que ocupa Caramoro I presenta una caída en vertical en buena parte de su trayectoria, con excepción de su lado oriental (Fig. 3). De este modo, la superficie máxima que delimita el muro de cierre del asentamiento no supera los $500 \mathrm{~m}^{2}$, habiendo empleado más de $250 \mathrm{~m}^{2}$ en su delimitación, con la construcción de diversas estructuras de gran porte, siendo muy destacado el empleo de la piedra. El acceso al asentamiento solamente se podría efectuar por una pequeña zona abierta, situada en su extremo nororiental.

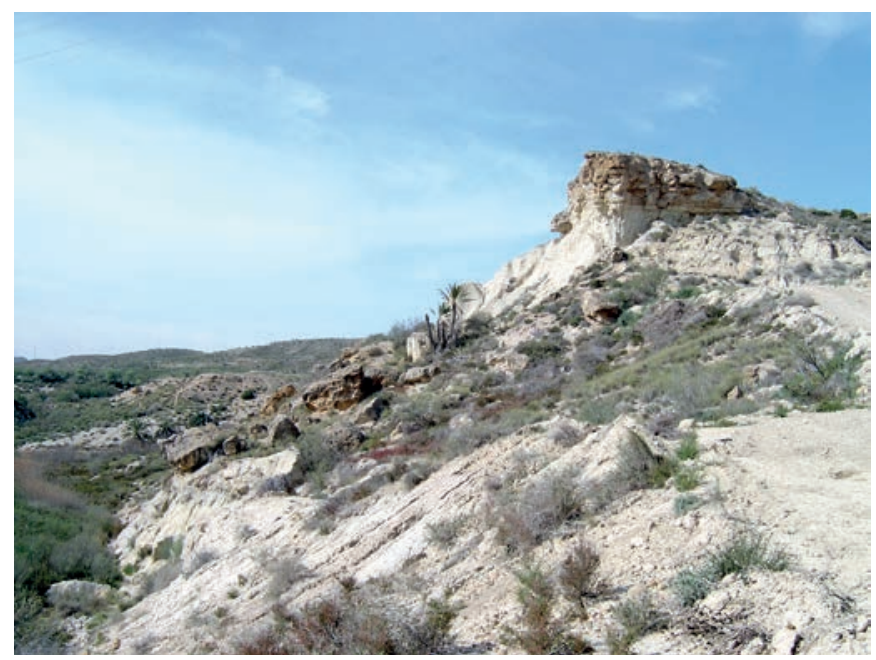

Figura 2. Caramoro I por su lado meridional y occidental visto desde el río.

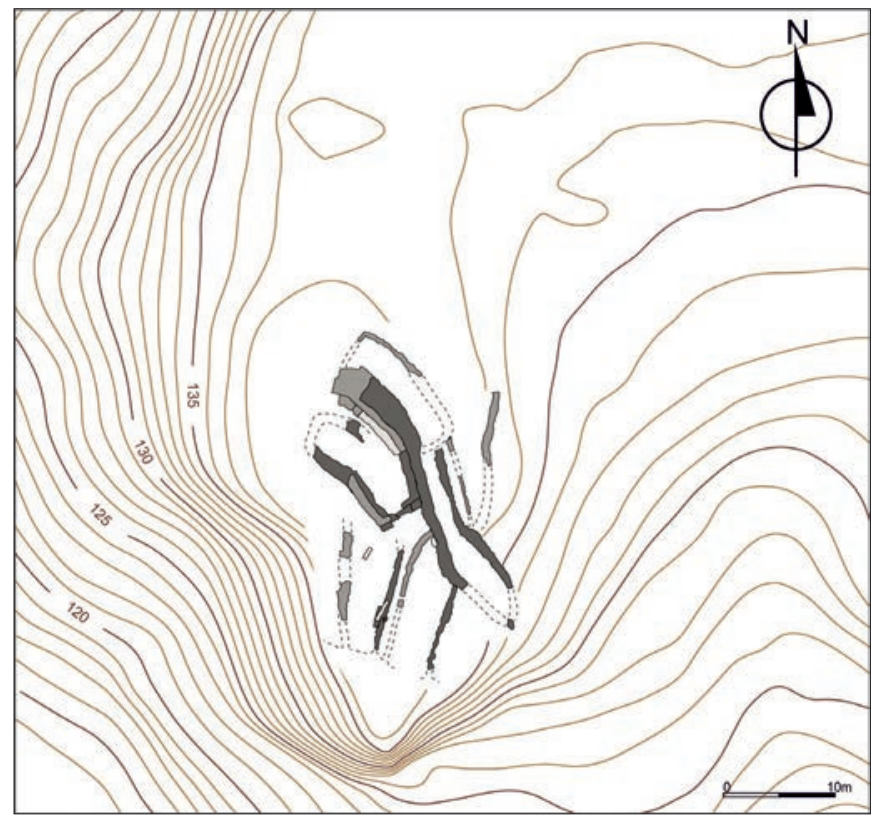

Figura 3. Plano topográfico de Caramoro I, con indicación de las curvas de nivel.

\section{LAS ACTUACIONES ARQUEOLÓGICAS EN CARAMORO I}

\section{Las excavaciones de R. Ramos Fernández en 1981}

Caramoro I fue objeto de su primera excavación durante el primer semestre de 1981, bajo la dirección de R. Ramos Fernández (1988). En una breve publicación dicho autor mostraba un croquis de la planimetría del asentamiento, así como una propuesta de interpretación. En los sondeos inicialmente practicados, el yacimiento presentaba, al menos, dos niveles de ocupación relacionables con dos pavimentos, a su vez amortizados bajo niveles de derrumbe en cerca de un metro de potencia estratigráfica. Tras una capa de superficie aparecía un primer nivel de derrumbe, seguido de otro que contenía más restos arqueológicos y que colmataban un pavimento de arcilla amarillenta pisada. Infrayacente a este pavimento, aparecía un importante nivel de incendio sobre otro pavimento de las mismas características que el anterior. Este pavimento se había levantado sobre un nivel de preparación que se asentaba directamente sobre la roca madre. No obstante, no fue posible apreciar diferencias entre el material arqueológico registrado en ambos niveles. 
En función de toda la documentación obtenida en los sondeos practicados se procedió a la excavación del yacimiento, implantando una cuadrícula de panal de orientación simple, con 25 sondeos de patrón divisibles en cuatro casillas de $2 \times 2 \mathrm{~m}$, con testigos de $0,50 \mathrm{~m}$ de anchura entre sondeos y de $0,25 \mathrm{~m}$ entre casillas, donde se repetía la sucesión estratigráfica observada en el sondeo de prospección (Ramos 1988).

Esta intervención hizo aflorar, según su excavador, los restos de un recinto de planta arriñonada adaptada a la superficie del terreno (Fig. 4) y con un revestimiento de barro arcilloso amarillento. Este recinto fue interpretado como un bastión, al estar formado por un muro principal en su extremo oriental que cerraba toda la edificación, al que se le habían ido adosando posteriormente diversos muros, tanto por su cara externa como interna, con un grosor que disminuía en dirección sur. Por su cara

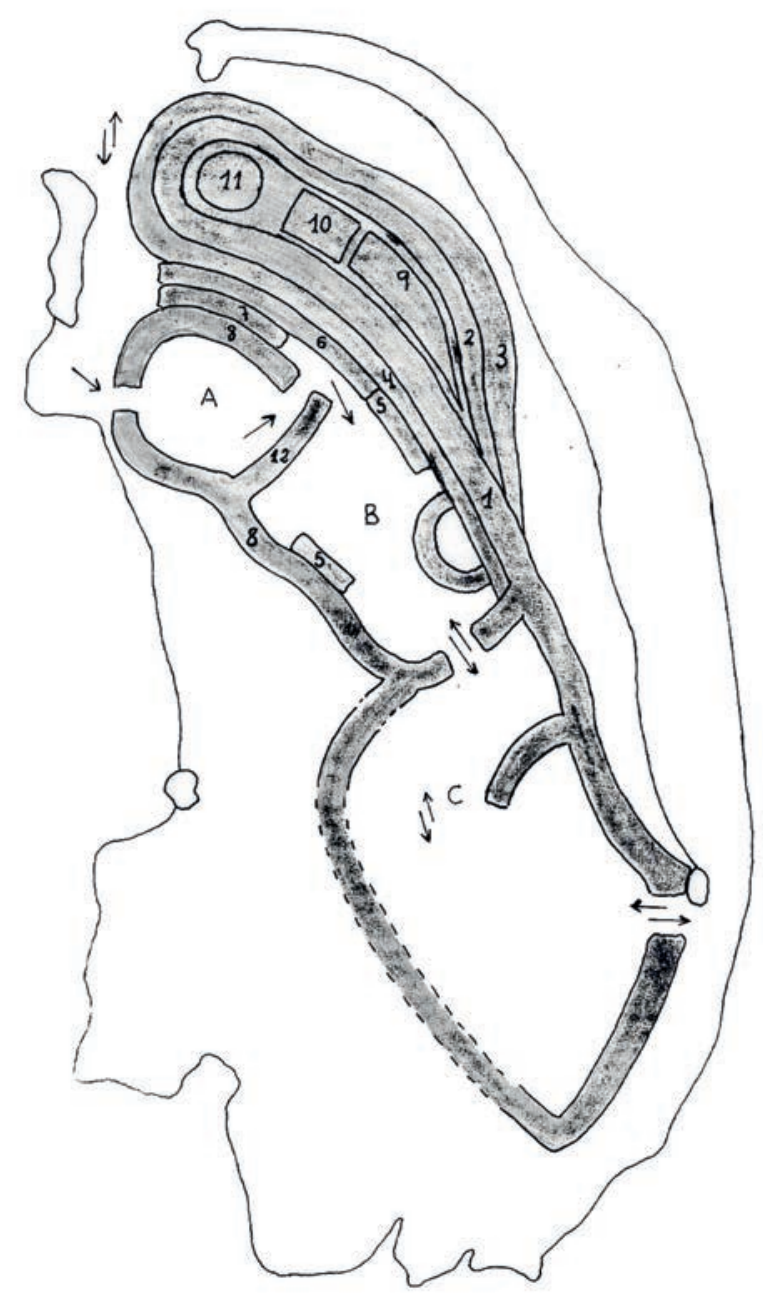

Figura 4. Croquis de Caramoro I elaborado por R. Ramos Fernández (1988). oriental, la adición de muros había dejado tres espacios abiertos entre ellos que, en sentido S-N, conformaban un espacio triangular en cuña relleno de piedras, una plataforma rectangular de $1,5 \times 2 \mathrm{~m}$ interpretada como los restos de una posible torre y un espacio semicircular relleno de piedras en el extremo septentrional. Por su cara occidental se adosaron otra serie de muros conformando dos habitaciones, denominadas A y B.

A la primera $-\mathrm{A}-$, interpretada como una estancia o vestíbulo de ingreso de planta circular y $3,5 \mathrm{~m}$ de diámetro, se accedía desde el exterior del poblado por medio de un estrecho pasillo en su ángulo noroeste de poco más de $1 \mathrm{~m}$ de anchura y que, por medio de un acceso en recodo en su extremo suroriental, daba acceso a la estancia central -B- (Fig. 5). Esta última, de planta irregular de $4 \times 6 \mathrm{~m}$ de superficie, presentaba un banco en su extremo occidental y oriental, respectivamente,

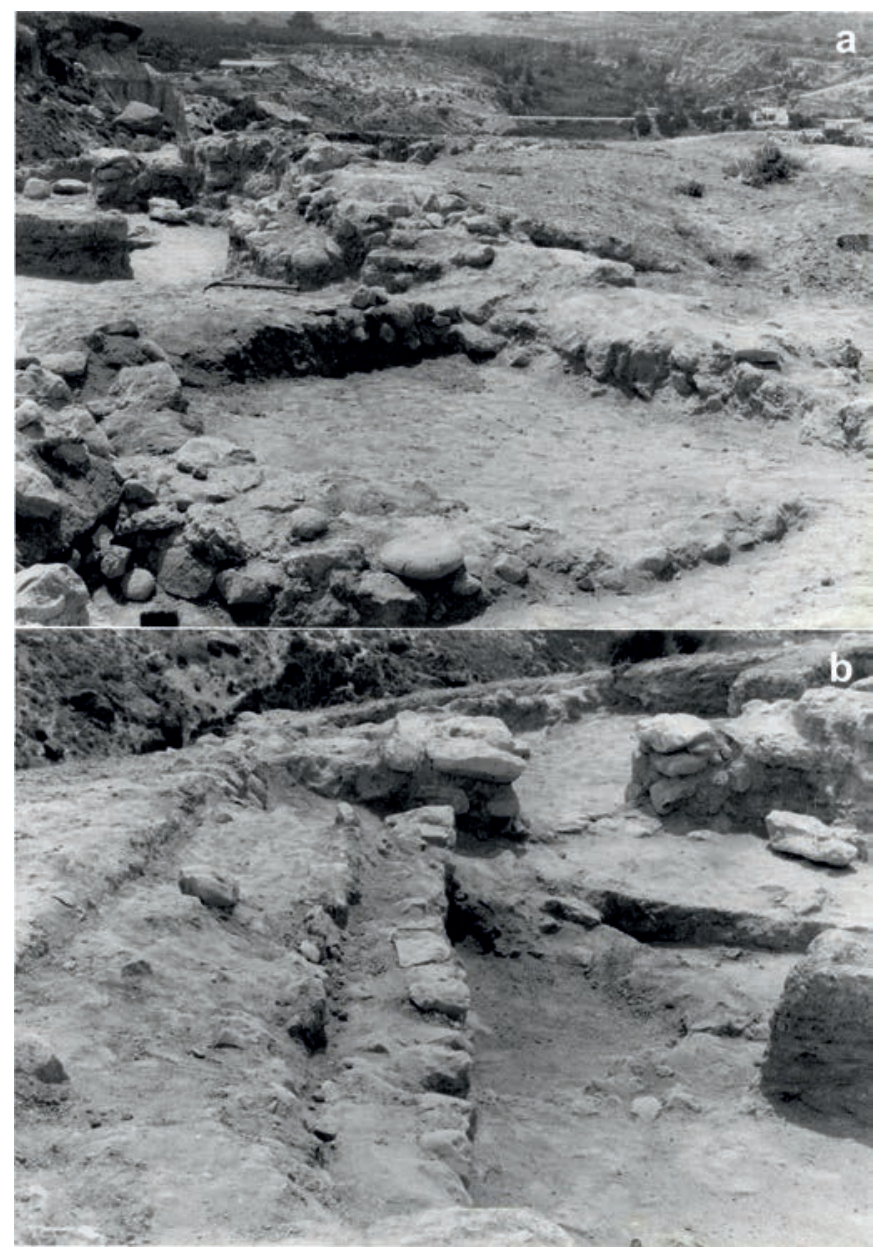

Figura 5. Fotografías de R. Ramos de la estancia A. a) en primer término la estancia $A$ de R. Ramos, con el muro medianero que la separaba de la estancia B y el banco occidental; b) Estancia B de Ramos -integrada en A en González y Ruiz (1995)- en la que se advierte la presencia del hogar de gran tamaño documentado. Fondo documental del Museo de Arqueología e Historia de Elche (MAHE). 
además de un hogar semicircular junto al banco del extremo oriental. En su extremo meridional presentaba una puerta de salida con portal enlosado y delimitación de jambas que daba acceso a una tercera estancia -Cidentificada como una terraza que no estaba cubierta y en la que sólo se identificó un estrato. Esta terraza tenía una puerta de comunicación del recinto con el exterior en el extremo sureste y un muro que obligaba a un ingreso en recodo a la estancia central -B-. El asentamiento fue interpretado como un "puesto vigía", construido en un punto de fácil defensa y gran visibilidad, correspondiente a las facies del Bronce Valenciano.

\section{Las intervenciones de A. González Prats y E. Ruiz Segura en 1989 y 1993}

Unos años más tarde, las obras realizadas para la construcción de la autovía A-7-motivaron una nueva excavación de urgencia iniciada en noviembre de 1989 bajo la dirección de A. González Prats y E. Ruiz Segura. Los resultados preliminares de esta intervención se publicarían al poco tiempo, abordando los nuevos datos arquitectónicos, la escasa información sobre la estratigrafía que presentaba el yacimiento y los nuevos elementos de cultura material, que obligaron a variar el ámbito cultural al que había sido adscrito (González y Ruiz 1995).

Las intervenciones arqueológicas llevadas a cabo permitieron considerar que el asentamiento contaba con una compleja fortificación, compuesta por un bastión $-\mathrm{H}-$ de forma arriñonada con unas dimensiones de $13,5 \times 3,5 \mathrm{~m}$ en su extremo nororiental, al que se adosaba en su extremo meridional una estrecha plataforma -F- o "cuerpo de guardia" y otro espacio de tipo fosa -G- interpretado como una canalización de desagüe. Finalmente, se detectaron los restos de un gran muro -I-, muy deteriorado y que no llegaron a excavar, que presentaba un trazado oblicuo en relación al resto de la construcción, con una longitud de $9 \mathrm{~m}$ (Fig. 6).

La construcción del bastión -H- se realizó con la colocación de gruesas piedras en talud en buena parte de su perímetro, quedando el resto cerrado por una serie de elementos de barro que se describen como de forma planoconvexa (Fig. 7). El interior presentaba un relleno homogéneo de piedras y barro que se alzaría $2 \mathrm{~m}$ y que serviría de zócalo a una superestructura ligera integrada por vegetales.

La plataforma $-\mathrm{F}$ - estaba construida por una línea simple de piedras en talud, con una orientación NO-SE en sus primeros $8 \mathrm{~m}$, y que, tras la realización de una trinchera para definir la orientación de este muro, se unía

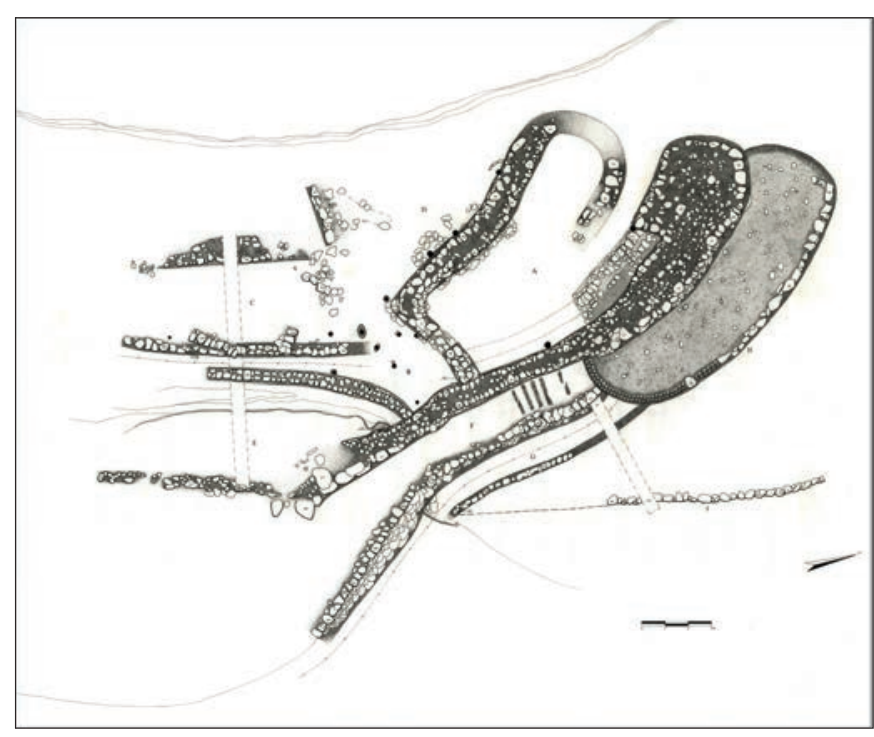

Figura 6. Planimetría de Caramoro I elaborada en 1993 por A. González y E. Ruiz (1995, p.106).

a otro tramo de muro de $8,5 \mathrm{~m}$ de longitud que realizaba una inflexión de $150^{\circ}$, alcanzando una altura superior a $\operatorname{los} 2 \mathrm{~m}$, estando revocado por una espesa capa de arcilla.

Paralelo al primer tramo de muro de la plataforma F discurría un estrecho muro de $0,3 \mathrm{~m}$ de anchura y 5,7 $\mathrm{m}$ de longitud, delimitando un foso $-\mathrm{G}^{-}$, de $1,2 \mathrm{~m}$ de amplitud y cuya superficie presentaba grandes lajas de piedra, que se iba estrechando en su extremo meridional hasta conectar con la plataforma $\mathrm{F}$ y que en su extremo septentrional conectaba con el bastión $\mathrm{H}$.

El sistema de fortificación se completaba con dos supuestas torres defensivas que configuraban un estrecho corredor de acceso al interior del poblado de apenas $1 \mathrm{~m}$ de anchura. A través de esta entrada se accedía a una serie de unidades habitacionales, con una estancia principal por donde discurría el acceso $-\mathrm{A}-\mathrm{y}$ un pequeño patio - $\mathrm{B}-$ a través del cual se accedía indistintamente al resto de unidades habitacionales $-\mathrm{C}, \mathrm{D}$ y E-.

La habitación o espacio A estaba constituida por las estancias A y B de la excavación de R. Ramos. No hay ninguna mención al muro central que dividiría esta habitación A en dos estancias, desaparecido probablemente fruto de la erosión y las agresiones antrópicas. En esta vivienda A, un potente muro oriental, de $4 \mathrm{~m}$ de anchura, se prolongaba hacia el extremo meridional, decreciendo en amplitud hasta alcanzar una anchura aproximada de $1 \mathrm{~m}$. Bajo el banco corrido documentado por R. Ramos en el extremo oriental de su estancia $\mathrm{B}$, aparecía otro banco corrido y un hoyo de poste correspondiente a la fase constructiva más antigua, y que 


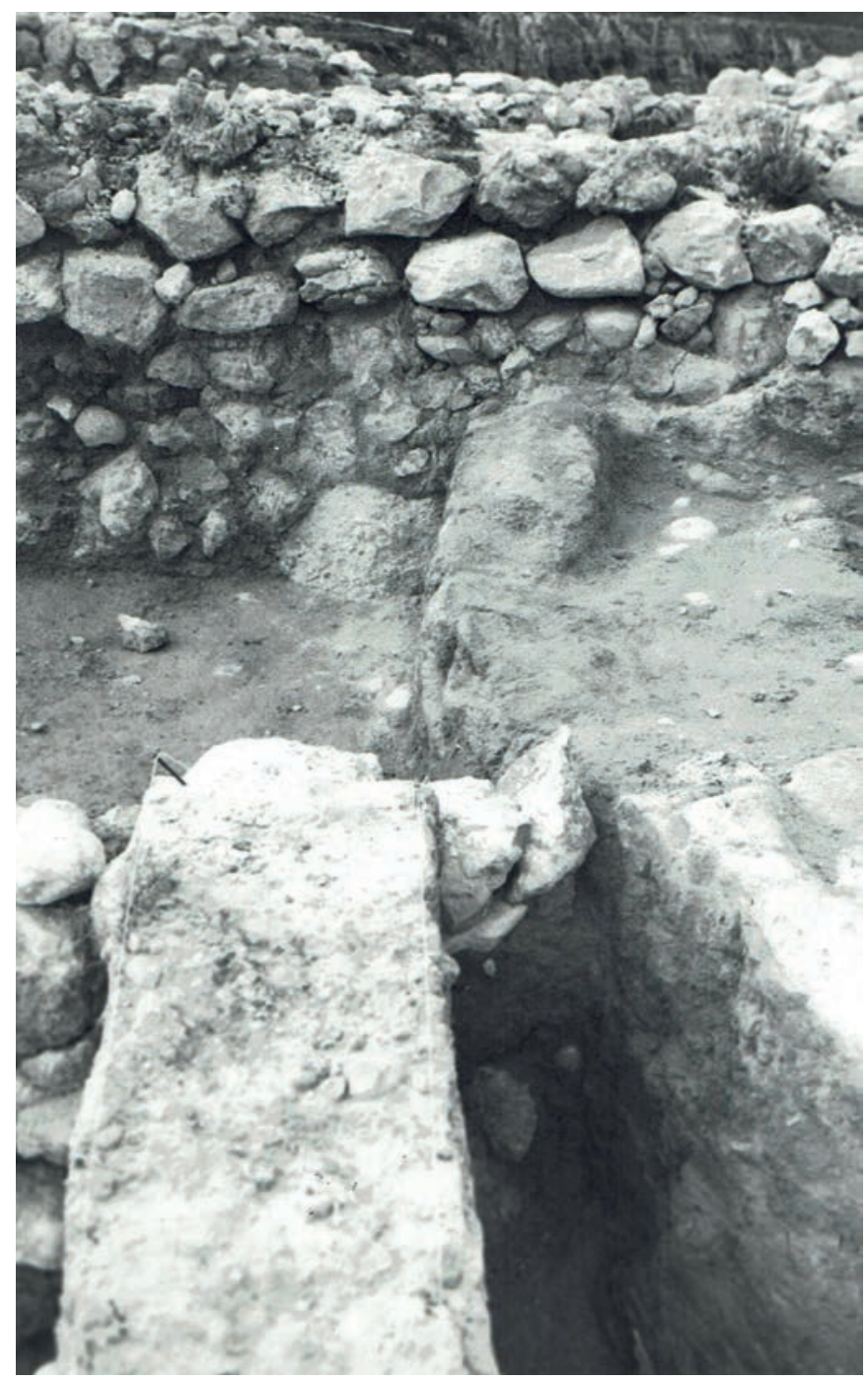

Figura 7. Revestimiento meridional de barro amasado de la plataforma F o bastión a la derecha y testigo $B$ en primer término a la izquierda. Fotografía efectuada en 1989 por parte de A. González y E. Ruiz. En el perfil de la plataforma puede observarse el contorno de algunas de las unidades de barro amasado que lo conformaban. Fondo documental del Museo de Arqueología e Historia de Elche (MAHE).

habría que considerar como infrapuestos al supuesto hogar registrado en la excavación realizada en 1981. Asimismo, esta habitación también presentaba un banco corrido en su extremo occidental.

Desde esta primera unidad habitacional y a través de un vano de $1 \mathrm{~m}$ de anchura aproximadamente se accedía a un nuevo espacio -B- de pequeñas dimensiones (ver Fig. 6), interpretado como un pequeño patio cubierto o porche con gran cantidad de calzos de poste $-7-$ y con un hogar situado en su extremo nororiental. Sin embargo, las excavaciones sólo documentaron un único derrumbe y finas capas de pavimento en esta zona, lo que hace pensar en una única fase constructiva. Los calzos de poste se encontraban a distinta altura y no parecían haberse construido al mismo tiempo, sino corresponder a continuas remodelaciones.

A través de este espacio abierto se accedía al resto de las dependencias. En el extremo occidental y en paralelo al espacio A, había un nuevo espacio definido como habitación $\mathrm{D}$, delimitado por el muro occidental de la habitación $\mathrm{A}$ y por los restos de otro que se sitúan en dirección E-SE a O-NO. En su extremo oriental pudo detectarse un nuevo banco corrido y varios suelos de hogares, así como calzos de poste, con abundante material arqueológico, entre el que destacaba una escudilla de madera carbonizada no conservada, varios colgantes de marfil y algunos punzones de hueso en una única fase constructiva. Parte de esta habitación había desparecido por el desprendimiento de la cresta rocosa en el extremo occidental del espolón. Esta circunstancia, unido a las grietas presentes en esta zona del yacimiento, habría hecho desaparecer parte de otra habitación en el extremo suroccidental, que no recibió denominación en la posterior publicación realizada.

Desde el espacio B o patio también se accedía a un nuevo espacio - C- en el extremo meridional del poblado, de planta rectangular y que, a pesar de presentar estratos correspondientes a una única fase de ocupación con varios pavimentos, restos de hogares y calzos de poste, presentaba al menos dos muros superpuestos al muro oriental original de la misma. Estos debían corresponder a una segunda fase constructiva totalmente arrasada por la erosión. En el lado oriental de esta habitación aparecía un estrecho corredor de $0,50 \mathrm{~m}$, interpretado como un conducto de evacuación del agua de lluvia procedente de la cubierta de esta vivienda y de la habitación E, así como del patio. A pesar de ello, en el interior de este espacio se documentaron restos de calzos de poste que podrían indicar que también este estuvo techado.

Al este de dicho corredor se situaba el espacio o habitación $\mathrm{E}$, que presentaba una estratigrafía indicativa de una única fase de ocupación, con un potente nivel de incendio que ofrecía una gran cantidad de material arqueológico. Presentaba una planta triangular, con dos hogares junto a su muro oriental. En el ángulo septentrional de esta habitación se detectó una fosa donde se había enterrado a un infante de unos 18 meses de edad aproximadamente, en el que se apreciaban las señales de un amplio corte en la parte frontal del cráneo producido por una hoja metálica de gran tamaño (Cloquell y Aguilar 1996; Jover et al. 2018).

Según sus excavadores, la cultura material documentada, el uso de la técnica constructiva denominada "espina de pez" y, fundamentalmente, la presencia de una inhumación bajo el suelo de la habitación E reflejaban, de 
manera incuestionable, el carácter argárico del yacimiento. Asimismo, su carácter fortificado tendría un sentido estratégico en relación al intenso poblamiento argárico del curso bajo del río Vinalopó (González y Ruiz 1995: 100).

De esta manera, el asentamiento de Caramoro I, excavado prácticamente en su totalidad, puesto que solamente quedaban dos pequeños testigos $-\mathrm{A}$ y B- de unos $50 \mathrm{~cm}$ de anchura en la zona interior y exterior, pasaba a la bibliografía como un pequeño fortín argárico del que, aunque no fuera realizada ninguna datación absoluta, se habían señalado dos momentos de ocupación sin cambios apreciables a nivel material.

\section{Últimas actuaciones arqueológicas: 2015 y 2016}

El interés de actuar nuevamente en este enclave residía en la posibilidad de documentar las estructuras conservadas, intentando efectuar una lectura estratigráfica de las mismas para entender de forma más completa el asentamiento, así como excavar los testigos estratigráficos dejados por las anteriores excavaciones, para recuperar información que permitiera reconocer su secuencia y concretar, al menos, el momento de su fundación.

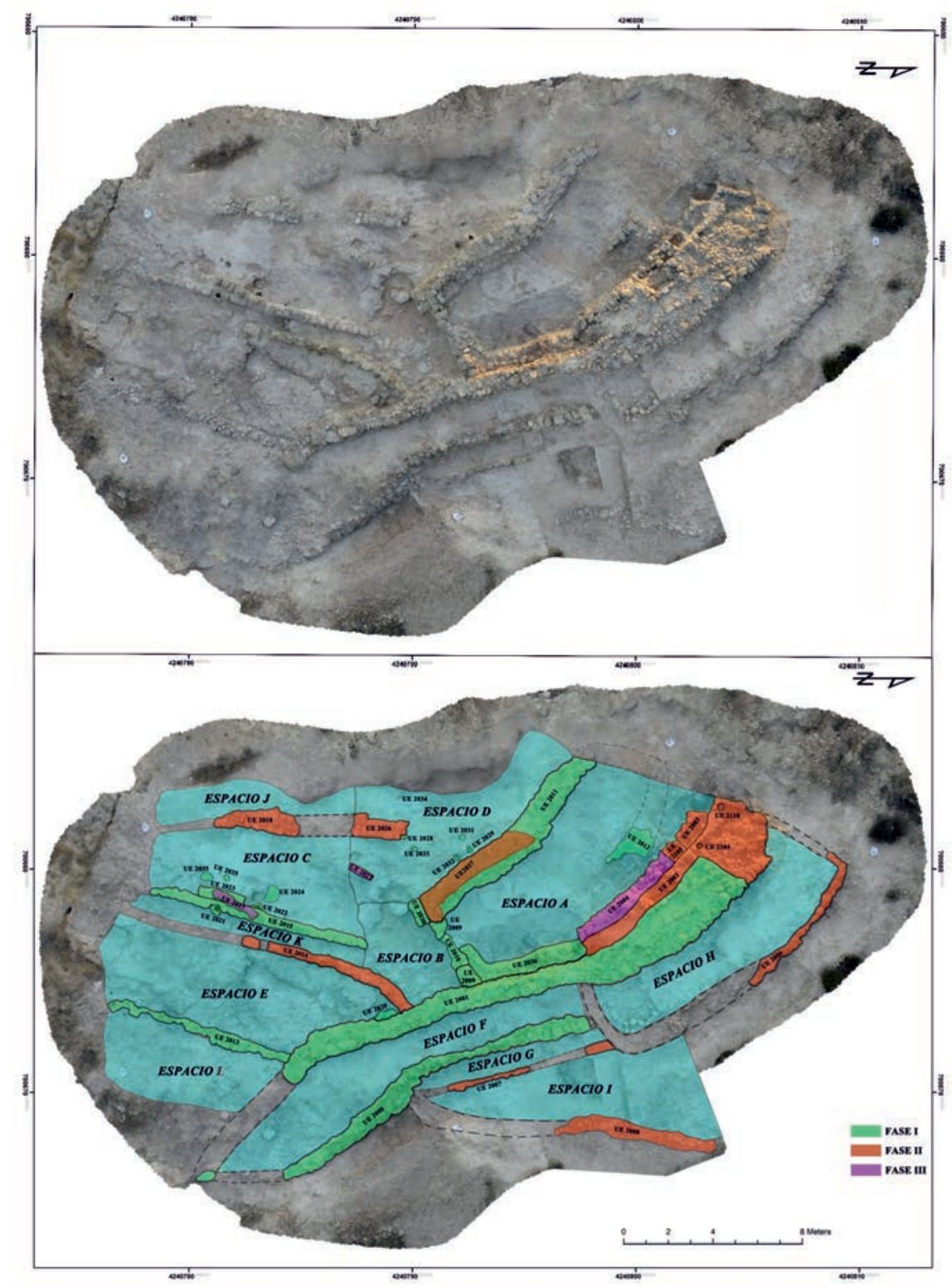

Figura 8. Ortoimagen de Caramoro I efectuada en 2016. Abajo: indicación a color de los espacios diferenciados y unidades estratigráficas reconocidas en la actuación de 2015-2016. 
Así, los trabajos de limpieza y documentación arqueológica fueron iniciados el día 29 de junio de 2015 y desarrollados hasta el 22 de julio de 2015 y se retomaron nuevamente hacia las mismas fechas en 2016. Los trabajos fotogramétricos y planimétricos obligaron a dedicar buena parte del tiempo a la limpieza de las estructuras $\mathrm{y}$ de los ambientes ya excavados. El tiempo restante fue dedicado a la excavación de los restos del testigo A conservado en el interior del asentamiento, así como de algunos retazos sedimentarios en la zona $\mathrm{D}$, algo alterados. La zona exterior también fue limpiada en parte para su fotogrametría, pero la conservación de parte del segundo de los testigos -B- con relleno sedimentario no alterado, aconsejó que su documentación fuese efectuada en 2016.

Durante la campaña realizada en 2015 se pudieron reconocer y definir los espacios A, B, C, D, E, F, G, H e $\mathrm{I}$, manteniendo las denominaciones de las excavaciones previas (Fig. 8). A ellos se incorporaron tres nuevos espacios: el espacio J, situado al O del muro UE 2018, el cual comprende un espacio de tendencia rectangular con unas dimensiones máximas de $9 \mathrm{~m}$ en el eje S-N y $1,55 \mathrm{~m}$ en el eje E-O, delimitando un área aproximada de $10,5 \mathrm{~m}^{2}$; el espacio L, ubicado intramuros al SE del muro UE 2013 y al S de lo que sería la prolongación del muro UE 2001, el cual comprende un área de aproximada de $23 \mathrm{~m}^{2}$ de tendencia rectangular; y el espacio $\mathrm{K}$, estrecho corredor que ya había sido identificado por A. González y E. Ruiz durante sus excavaciones, pero que no había sido definido de forma independiente al resto de espacios.

\section{LECTURA SECUENCIAL Y DESARROLLO CONSTRUCTIVO DE CARAMORO I}

La labor de campo emprendida en 2015 y 2016 ha permitido fijar con mucha mayor precisión el proceso de construcción y ocupación del asentamiento. A través de la limpieza y excavación puntual en algunas zonas del asentamiento -testigos A y B, restos sedimentarios en el espacio $\mathrm{D}$, zona de acceso e interior en el espacio $\mathrm{A}-\mathrm{y}$ de la lectura estratigráfica de las estructuras murarias, se han podido determinar y reconocer, al menos, tres momentos de uso. No obstante, en general, la planificación espacial y la estructura arquitectónica del sitio no se transformaron en su esencia desde su fundación.

Los diferentes momentos de uso detectados se concretan, básicamente, en ampliaciones, refuerzos murarios, reformas y saneamientos de determinados espacios. En algunos casos, la causa que pudo ocasionar la necesidad de emprender reformas fueron incendios que obligaron a reacondicionar el espacio. Así, tanto en las excavaciones iniciales como en las últimas actuaciones, en los espacios A y E han sido detectados niveles de incendio sobre las pavimentaciones más antiguas, habiéndose conservado, además, algunas evidencias materiales de facto y basura primaria (Schiffer 1985).

\section{La fundación de Caramoro I y el primer momento de uso}

La trama del asentamiento se configura a través de la construcción de un gran muro longitudinal -UE 2001-, asentado sobre la base geológica de calizas bioclásticas, que siguiendo las curvas de nivel se prolonga ligeramente de $\mathrm{NO}$ a SE a lo largo de algo más de $30 \mathrm{~m}$. Este muro no se conserva en su extremo más meridional, como consecuencia de los procesos erosivos de ladera (Fig. 9). No obstante, se prolongaría hasta empatar con un gran bloque natural, cerrando totalmente el acceso al asentamiento por este extremo. Este gran muro de doble cara, que sirve de delimitación y cierre del asentamiento, presenta una anchura media cercana a 1,20 m, aunque en el tercio más septentrional, justamente cuando la pendiente natural va aminorando, se va ensanchando hasta superar los $2,50 \mathrm{~m}$. La altura conservada alcanza en algunos tramos $0,90 \mathrm{~m}$.

En su zona septentrional el muro acaba de forma rectilínea, dejando un espacio de acceso al área habitada de algo más de $4 \mathrm{~m}$. Este espacio constituye el único acceso al interior del asentamiento. Como refuerzo a este muro, especialmente en su extremo central y meridional, fue creada una gran plataforma de aterrazamiento contenida por un antemural ataludado -UE 2000- levantado con bloques de gran tamaño, que en algún caso superan el metro. En sí, este antemural es un muro de aterrazamiento de distinta anchura, que conserva algo más de $2 \mathrm{~m}$ de altura y casi $4 \mathrm{~m}$ de ancho en la zona meridional, precisamente donde el muro principal de cierre hace una mayor inflexión y la pendiente es más acusada. Además, conserva más altura $-\mathrm{y}$ también anchura-, cercana a los 2,5 m, allí donde la construcción en su conjunto más lo requiere en relación directa con el incremento de la pendiente. Por último, cabe señalar que el antemural estaría totalmente enfoscado o revestido por una gruesa capa de arcillas verdosas, perfectamente alisada, cuyo grosor oscilaba entre 12 y $18 \mathrm{~cm}$. Este revestimiento mantendría la disposición ataludada hasta empatar con el suelo de circulación detectado.

El espacio delimitado por el muro principal -UE 2001- permitía planificar urbanísticamente un área con 


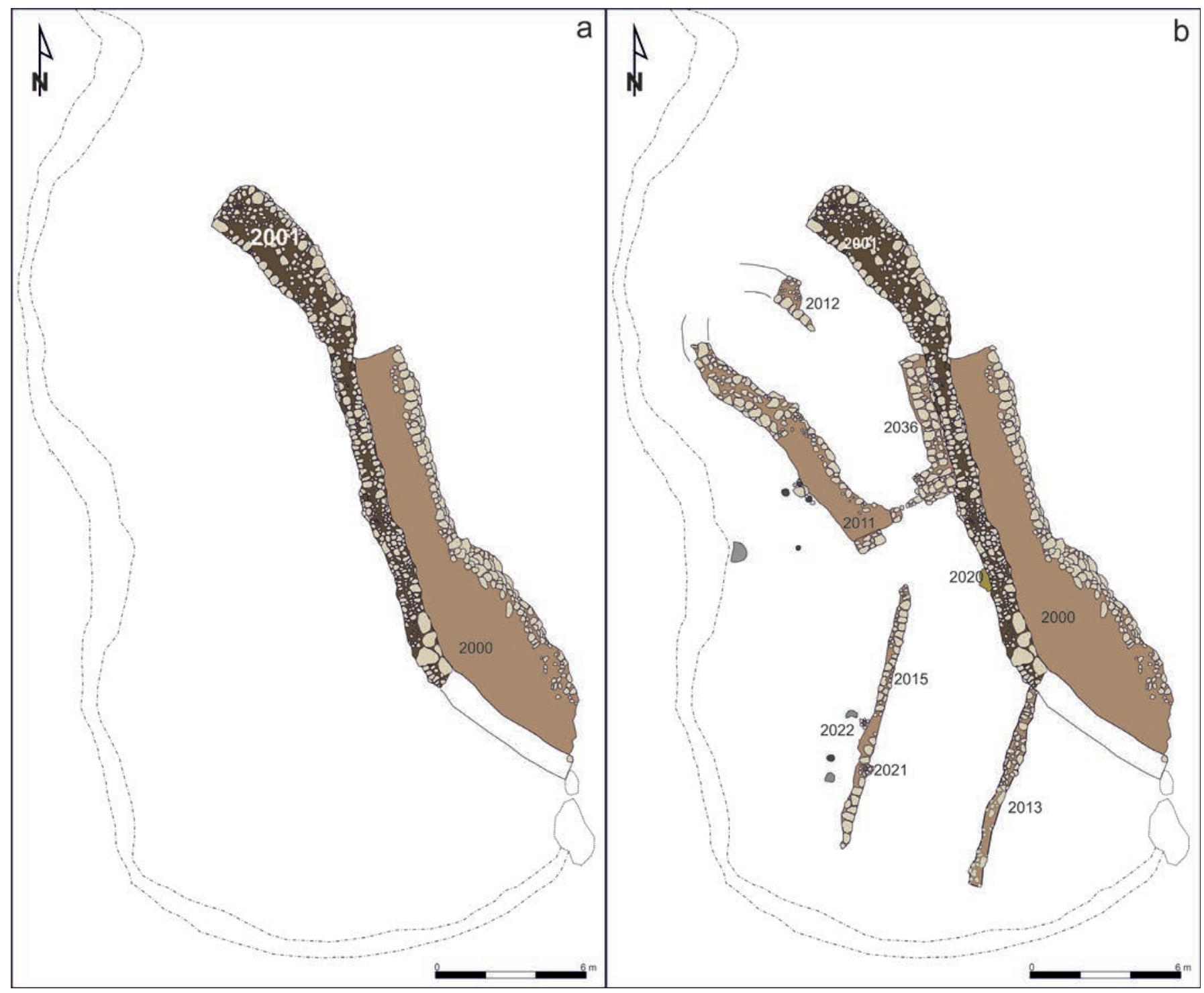

Figura 9. Planta de la secuencia constructiva de Caramoro I. a) Muro inicial de delimitación del área de asentamiento; b) Estructuras de la primera fase constructiva de y ocupación.

una ligera pendiente e infranqueable por su lado occidental y meridional, cercano a los $500 \mathrm{~m}^{2}$, lo que se tradujo, una vez construidos los distintos edificios, en una superficie útil en torno a los $420 \mathrm{~m}^{2}$. El acceso a los mismos solamente se podía efectuar por una estrecha franja situada en el extremo nororiental (Fig. 10).

A partir de la documentación de distintos tramos murarios y de la información de sus excavadores, la distribución efectuada consistió en la construcción de distintos edificios, aunque el principal articulador de todo el espacio fue el denominado como espacio A. Se trata de un edificio de planta rectangular alargada, con su extremo septentrional absidal. El vano de ingreso se configuraría en su extremo nororiental, con una anchura inicial de aproximadamente 1,60 m. Este edificio, levantado con gruesos muros de piedra y margas verdosas, tendría una estancia con una superficie útil de unos $34 \mathrm{~m}^{2}$, pavimentada solo parcialmente, aprovechando en parte la roca como suelo. Asimismo, contaría con un gran banco corrido en "L invertida" en su extremo suroriental. En el muro meridional del edificio fue planificado un vano escalonado con el objeto de acceder al resto de espacios meridionales.

Este edificio fue reacondicionado como consecuencia de un incendio -UE 1007 y 1003 de nuestras excavaciones en 2016-. De dicho evento pudimos comprobar la conservación de una mínima parte del derrumbe -UE 1005- y del ajuar conservados como basura de facto en la zona del banco suroriental (Fig. 11). La presencia de un buen número de objetos muebles de diversa naturaleza, además de otros obtenidos en 


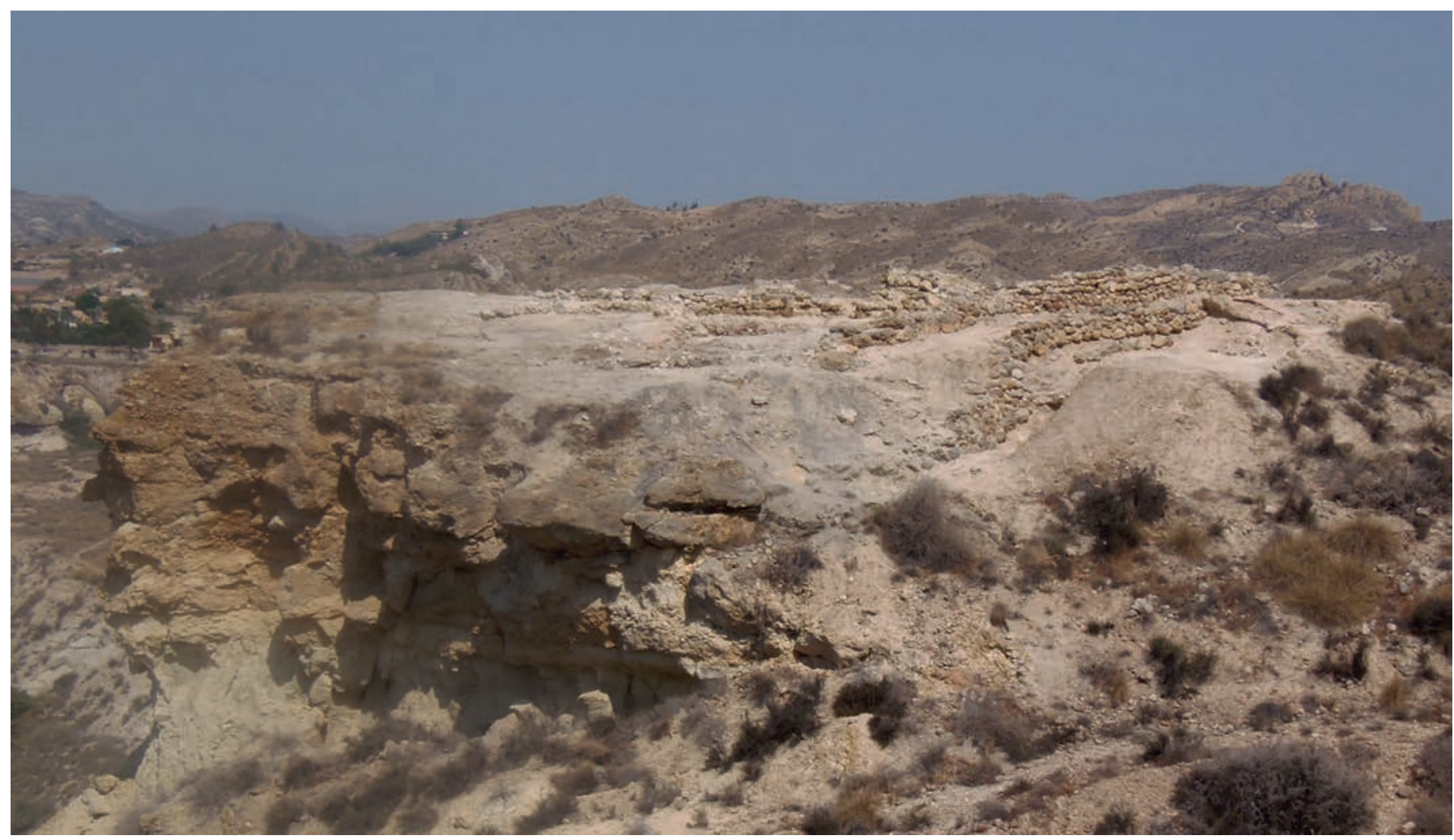

Figura 10. Vista exterior desde el sureste del antemural y muro principal de Caramoro I.

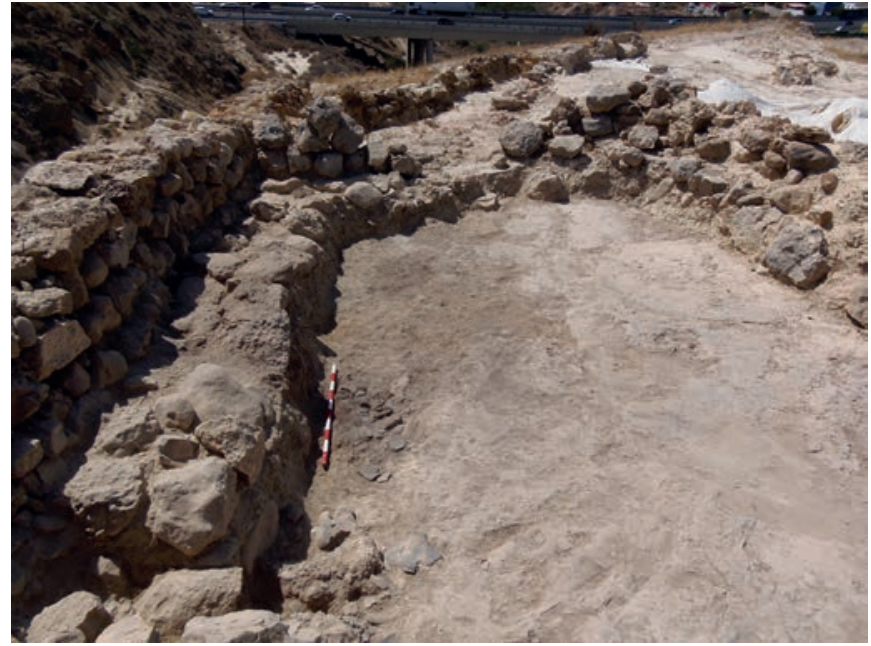

Figura 11. Banco suroriental con disposición en $L$ invertida en el que todavía se pueden ver algunos restos materiales conservados sobre el pavimento 1002 de la estancia A.

las diferentes excavaciones efectuadas con anterioridad, ha mostrado que en su interior se efectuarían entre otras actividades la molturación de cereales, la producción textil, dada la presencia de pesas de telar, junto a diversas labores de mantenimiento y consumo alimenticio. Las dataciones absolutas obtenidas a partir de dos muestras de vida corta procedentes de la pavimentación inicial de este espacio (Beta-446590: 3580 $\pm 30 \mathrm{BP}$ ) y del nivel de incendio superpuesto (Beta446589: $3580 \pm 30 \mathrm{BP}$ ) han mostrado el mismo rango cronológico, por lo que la distancia temporal entre su construcción e incendio tuvo que ser muy breve, a inicios del II milenio cal BC.

Desde el vano meridional del espacio A se accedía al denominado espacio $\mathrm{B}$, una zona de tendencia pseudocuadrangular que serviría como distribuidor al resto de edificios. A través de la construcción de simples muros medianeros con disposición SO-NE, fueron delimitados distintos edificios $-\mathrm{C}, \mathrm{D}, \mathrm{E}$ y L-.

Del espacio B (Fig. 12), del que no sabremos si formaría parte de otros espacios colindantes, sí podemos asegurar que estaría cubierto, dada la presencia de diversos calzos de poste documentados en las excavaciones de A. González y E. Ruiz. De igual modo, a partir de la información anotada por Ruiz en el diario de excavación de 1989, se constató la presencia de diversos lentejones de tierras cenicientas, lo que aseguraría la presencia de hogares en el mismo. Además, lo único que podemos señalar es la presencia de un pequeño banco adosado al muro meridional de la estancia $\mathrm{A}$. 


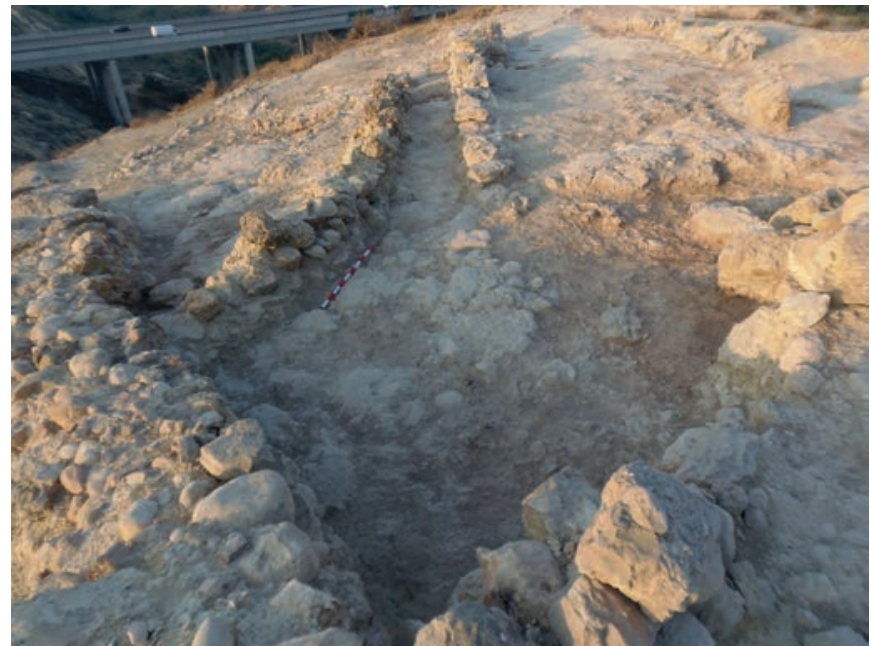

Figura 12. Vista desde el noreste del espacio B de A. González y E. Ruiz. Limpieza efectuada en 2015.
Desconocemos si el muro que separaría los espacios C y E -UE 2015- conectaría con el muro occidental del edificio A, tal y como Ramos (1988) indicaba en sus croquis. Por un lado, al oeste de este muro, encontraríamos el denominado espacio $\mathrm{C}$, del que no conocemos sus límites ni nororientales ni suroccidentales; mientras que hacia su lado oriental se definiría el espacio E, integrado por los muros 2015, 2013 y un pequeño tramo del muro 2001. En este espacio E es donde fue excavada la fosa de inhumación de un infantil, cuya datación (Beta-464794: $3620 \pm 30$ BP) muestra un cierto solapamiento con las obtenidas en los espacios A y D (Fig. 13). Del mismo modo, el espacio más meridional y oriental del asentamiento, el L, quedaría delimitado entre el muro 2013 y el tramo meridional del muro 2001.

\begin{tabular}{|c|c|c|c|c|c|c|c|}
\hline Laboratorio & Contexto & Momento & Muestra & D13C & Fecha BP & $1 \sigma$ & $2 \sigma$ \\
\hline $\begin{array}{l}\text { Beta- } 446590 \\
\text { CMI-03 }\end{array}$ & $\begin{array}{c}\text { UE } 1002 . \\
\text { Pavimento Espacio } \\
\text { A. Construcción } \\
\text { Fase I }\end{array}$ & $\begin{array}{l}\text { Material de } \\
\text { Construcción } \\
\text { momento } 1\end{array}$ & $\begin{array}{l}\text { Metacarpo IV. } \\
\text { Sus domesticus. } \\
\text { Menos de } 2 \text { años }\end{array}$ & $-19.70 / 00$ & $3580 \pm 30$ & $1965-1889$ & $2028-1828$ \\
\hline $\begin{array}{c}\text { Beta-419055 } \\
\text { CMI-01 }\end{array}$ & $\begin{array}{c}\text { UE } 1506 . \\
\text { Pavimento Espacio } \\
\text { D. Construcción } \\
\text { Fase I }\end{array}$ & $\begin{array}{l}\text { Material de } \\
\text { construcción } \\
\text { momento } 1\end{array}$ & $\begin{array}{l}\text { Fragmento distal } \\
\text { tibia ovicaprino } \\
\text { juvenil }\end{array}$ & $-18.70 / 00$ & $3570 \pm 30$ & $1956-1884$ & $2022-1781$ \\
\hline $\begin{array}{c}\text { Beta-446589 } \\
\text { CMI-02 }\end{array}$ & $\begin{array}{c}\text { UE 1007. Nivel } \\
\text { de incendio sobre } \\
\text { pavimento. Espacio } \\
\text { A. Fase I }\end{array}$ & $\begin{array}{c}\text { Basura Abandono } \\
\text { momento } 1\end{array}$ & $\begin{array}{c}\text { Vértebra } \\
\text { torácica. Cerphus } \\
\text { Elaphus }\end{array}$ & $-19.80 / 00$ & $3580 \pm 30$ & $1965-1889$ & $2028-1828$ \\
\hline $\begin{array}{l}\text { Beta-505646 } \\
\text { CMI-06 }\end{array}$ & $\begin{array}{l}\text { UE 1303. Inv. } 2 \text {. } \\
\text { CMI-15. Basura de } \\
\text { relleno empleada } \\
\text { para acondicionar } \\
\text { el segundo } \\
\text { momento de } \\
\text { construcción }\end{array}$ & $\begin{array}{l}\text { Basura momento } \\
1 \text { reutilizada }\end{array}$ & $\begin{array}{l}\text { Fragmento de } \\
\text { extremidad de } \\
\text { O/C }\end{array}$ & $-19.10 / 00$ & $3630 \pm 30$ & 2030-1948 & $\begin{array}{c}2045-1905 \\
(86.4 \%) \\
2127-2090 \\
(9 \%)\end{array}$ \\
\hline $\begin{array}{l}\text { Beta-464794 } \\
\text { CMI-05 }\end{array}$ & $\begin{array}{c}\text { Espacio E. } 1989 . \\
\text { B7. tumba }\end{array}$ & Uso momento 1 & $\begin{array}{l}\text { Individuo } \\
\text { infantil. } \\
\text { Esferoides }\end{array}$ & $-18.00 / 00$ & $3620 \pm 30$ & $2025-1943$ & $\begin{array}{c}2040-1894 \\
(91.6 \%) \\
2118-2097 \\
(3.8 \%)\end{array}$ \\
\hline $\begin{array}{l}\text { Beta-464793 } \\
\text { CMI-04 }\end{array}$ & $\begin{array}{l}\text { UE 1503. Fase } \\
\text { III. Derrumbe del } \\
\text { espacio D entre } \\
\text { tramos de muros }\end{array}$ & $\begin{array}{l}\text { Basura de } \\
\text { abandono } \\
\text { momento } 2\end{array}$ & $\begin{array}{l}\text { Fragmento } \\
\text { de tíbia de } \\
\text { ovicaprino }\end{array}$ & $-19.00 / 00$ & $3550 \pm 30$ & $\begin{array}{c}1945-1878 \\
(57.1 \%) \\
1840-1826 \\
(6.9 \%) \\
1793-1784 \\
(4.2 \%)\end{array}$ & $\begin{array}{c}1976-1861 \\
(67.7 \%) \\
1853-1772 \\
(26.9 \%) \\
2009-2002 \\
(0.8 \%)\end{array}$ \\
\hline $\begin{array}{c}\text { Beta-510335 } \\
\text { CMI-07 }\end{array}$ & $\begin{array}{l}\text { UE 1501. Espacio } \\
\text { D. CMI-15. } \\
\text { Momento final de } \\
\text { abandono }\end{array}$ & $\begin{array}{l}\text { Basura abandono } \\
\text { momento } 3\end{array}$ & Hordeum vulgare & $-23.20 / 00$ & $3510 \pm 30$ & $\begin{array}{c}1887-1867 \\
(0.199 \%) \\
1848-1774 \\
(0.801 \%)\end{array}$ & 1916-1749 \\
\hline
\end{tabular}

Figura 13. Relación de dataciones absolutas obtenidas de diversas muestras recuperadas en Caramoro I. 
La coetaneidad de los muros que configuran los diversos espacios a los que se ha hecho referencia -UUEE 2015 y 2013- se apoya en varios argumentos. El primero es el hecho de que ambos muros, el 2013 y el 2015, arrancan directamente de la roca madre, cosa que no ocurre con el resto de tramos murarios detectados y conservados en estos espacios; en segundo lugar, que ambos muros presentan una disposición NE-SO, siendo plenamente rectilíneos y paralelos entre ellos; en tercer lugar, presentan una equidistancia claramente planificada en la distribución del espacio construido; la anchura de ambos muros, unos $0,50 \mathrm{~m}$, y la técnica constructiva son las mismas; $y$, además, en su construcción fueron empleados bloques calizos, materia prima distinta a la habitualmente utilizada en el resto de muros, que son de conglomerados.

En cualquier caso, la mejor cantidad de información corresponde al espacio C. De la excavación de los restos desmoronados del testigo $\mathrm{A}$, se puede indicar que al primer momento corresponde la construcción de diversos calzos de poste, algunos de ellos, asociados claramente a los muros conservados. $\mathrm{Y}$, al mismo tiempo, también corresponderían dos hogares ovalados practicados en la pavimentación inicial de este espacio-UE 1207-. Uno de ellos se localiza en el extremo más occidental del espacio $\mathrm{C}$, mientras que el segundo se localiza a escasa distancia del muro 2015.

El pavimento 1207 tiene su continuidad en el espacio D con la detección de otros tramos pavimentados -UE 1506-. A este último corresponde la datación absoluta efectuada sobre una muestra de vida corta (Beta-419055: $3570 \pm 30$ BP). La fecha de construcción del primer pavimento de la zona viene a coincidir plenamente con las dataciones obtenidas en el espacio A. Ello implica aceptar que las primeras pavimentaciones y, probablemente, también la construcción del resto del asentamiento, se llevarían a cabo a inicios del II milenio cal BC.

\section{Las primeras remodelaciones: el segundo momento de uso}

Durante la primera de las remodelaciones -segundo de los momentos de uso con reformas- se produjeron las mayores transformaciones y ampliaciones en $\mathrm{Ca}$ ramoro I. A este momento, poco tiempo después de la construcción del asentamiento a inicios del II milenio cal BC, corresponde la ampliación-refuerzo del muro 2001 en su extremo septentrional, consistente en el alzado de un gran contrafuerte pétreo con planta de tendencia cuadrangular -UE 2002A- de unos 3,20 x $2,8 \mathrm{~m}$ de lado, al que se añadía un nuevo muro de refuerzo -2002B- adosado al muro 2001 en su cara occidental. Se creaba así una ampliación a modo de refuerzo del muro principal con planta en "P", prolongando en más de $2,8 \mathrm{~m}$ su trazado y reduciendo considerablemente las posibilidades de acceso al asentamiento (Fig. 14).

Acompañando dicha ampliación, fue construida y adosada, en el tercio septentrional del trazado del muro principal de cierre por su cara externa, una gran plataforma a modo de contrafuerte o bastión con forma de arco de círculo -UE 2006, configurando el espacio $\mathrm{H}-$ de unos 14,20 m de longitud con dirección SO-NE, una anchura máxima de unos $3,35 \mathrm{~m}$, conservando una altura de casi $0,60 \mathrm{~m}$. Esta construcción viene a coincidir en su desarrollo con el tramo de mayor anchura del muro de cierre, finalizando justamente donde se iniciaría el antemural. Según Ramos (1988) estaba recubierto por una capa de barro en todo el trazado de su cara superior. Como refuerzo del tramo de conexión entre el antemural y este nuevo contrafuerte también fue construida un nuevo muro-plataforma cercana a $1 \mathrm{~m}$ de anchura. El espacio I entre los muros 2007 y la plataforma 2008 fue nuevamente pavimentado o nivelado, generando un nuevo nivel de uso -UE 1812- (Fig. 15).

Al mismo tiempo, en el interior del asentamiento también se efectuaron diversas reformas. En el espacio A, al refuerzo en "P" se le añadió un banco en la zona de acceso, reduciendo considerablemente las dimensiones del vano. La presencia de tres postes de gran porte en esta zona de acceso -dos dispuestos en paralelo en ambos extremos de la cara occidental del nuevo contrafuerte y uno en el banco- permite plantear su techado. Mientras, en el ángulo sureste se construiría un gran hogar de tendencia semicircular, que fue excavado y levantado por Ramos en sus excavaciones. Elaborado con barro, presentaba un realce creado con piedra trabada.

En el resto del área ocupada, se configurarían tres nuevos espacios a partir de la construcción de al menos dos nuevos muros. La construcción del muro 2014 arrancaría directamente del muro de cierre y, con un desarrollo curvo en su trayecto inicial, se extendería de forma paralela al muro 2015 en su tramo meridional, configurando el espacio $\mathrm{K}$ a modo de pasillo. Y, por otro lado, a oriente del muro 2015 se 


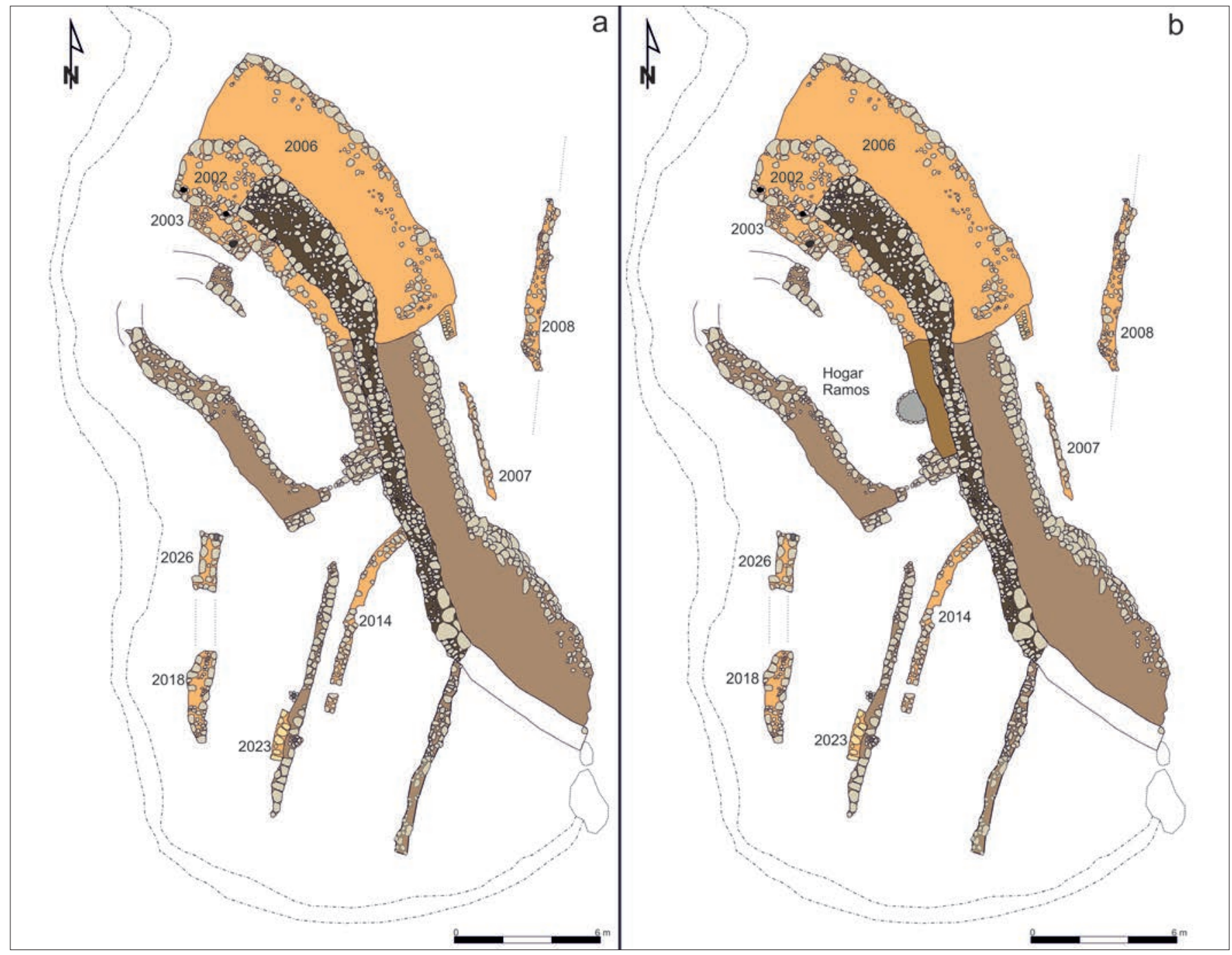

Figura 14. Planta acumulativa de la secuencia constructiva de Caramoro I. Primeras remodelaciones constructivas y segundo momento de uso. a) En amarillo, las nuevas estructuras, indicadas además con el número de unidad estratigráfica asignado; b) Representación de las estructuras de Caramoro I durante el segundo de los momentos con indicación del hogar documentado por R. Ramos en el interior de la estancia A.

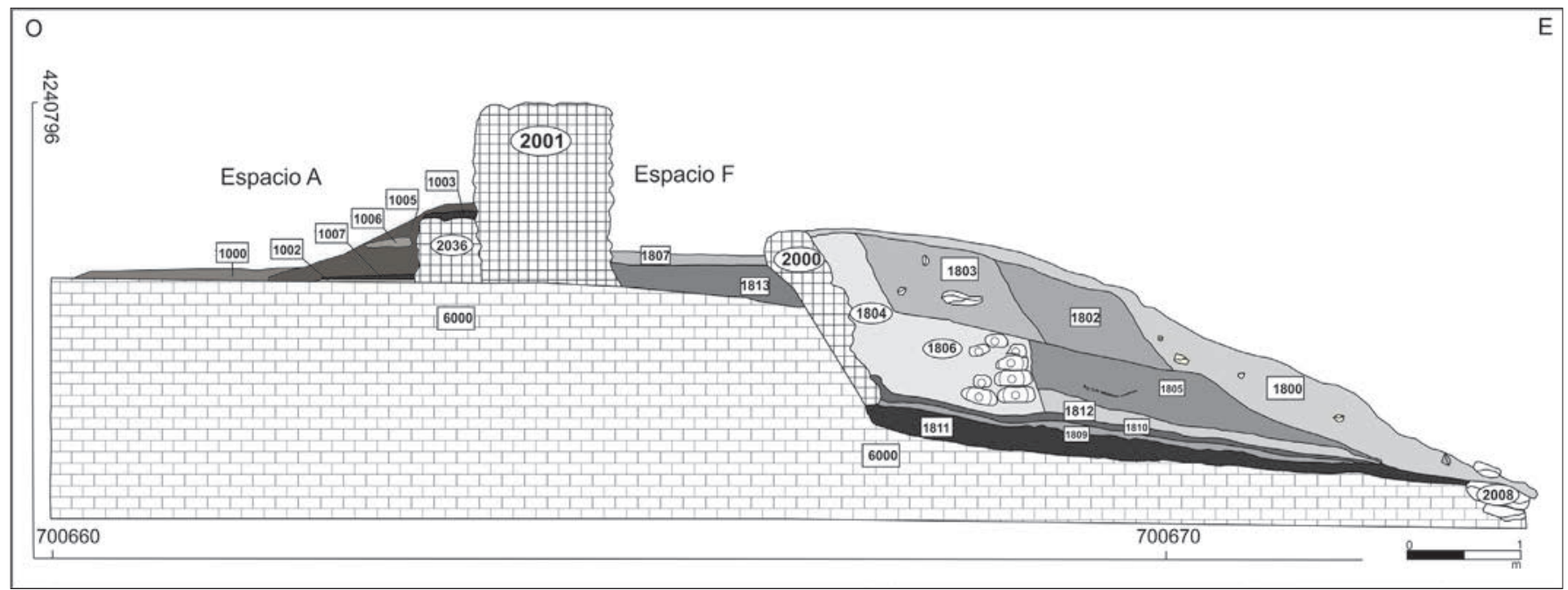

Figura 15. Sección O-E de los espacios $A$ y F, en la que se muestra la estratigrafía conservada, indicando las unidades estratigráficas reconocidas en el proceso de limpieza y excavación del perfil B. 
construyó otro muro, del que se conservan dos tramos -2018 y $2026-$, superpuesto a los tramos del pavimento inicial -UUEE 1207/1506-. Este muro, más ancho que los muros iniciales y elaborado, al igual que el muro 2014, con bloques de conglomerado, presenta una disposición $\mathrm{N}-\mathrm{S}$, reduciendo el espacio $\mathrm{C}$ y generando la creación de un nuevo espacio útil a oriente de los anteriores, el J.

Por lo demás, el espacio $\mathrm{C}$ continuó siendo utilizado de igual modo que en el primer momento de uso, al documentarse la construcción de un banco adosado-UE 2023- y un nuevo hogar -UE 2024-.

\section{Últimas reformas y acondicionamientos}

Desconocemos en qué momento preciso sería abandonado Caramoro I. No obstante, en el registro estratigráfico se han podido documentar otras remodelaciones que permiten sostener la existencia en el mismo de, al menos, un tercer momento de uso con reformas. Son varias las zonas del asentamiento donde han sido documentados tramos de muros correspondientes a este tercer momento, en la mayor parte de los casos superpuestos a otros que estuvieron en uso durante los momentos previos.

En los espacios H, I y G extramuros, justo en la zona de conexión entre la plataforma 2006 y el arranque del antemural, detectamos el reacondicionamiento de la zona mediante el forrado con barro del espacio de unión entre ambos -1807- (Fig. 16a, ver también Fig. 7), la creación de un murete o pequeña plataforma de bloques de barro amasados -1806- (Fig.16b) que, discurriendo en paralelo con el muro 2007; y, por último, un enlucido de barro de considerable grosor en el antemural -UE 1804-(Fig.16b). Este murete o plataforma de barro estaría integrado por bloques amasados superpuestos, de diversos tamaños. Además, se creó una nueva pavimentación en el espacio I -UE 1810-, conectando los muros 2007 y 2008. El abandono de este espacio viene atestiguado por el paquete sedimentario 1805 y la caída y erosión de parte del enlucido del antemural -UUEE 1802 y $1803-$ (ver Fig. 15).

El espacio A también sufrió diversas reformas, aunque en este caso solamente podemos inferirlas a partir de los documentos fotográficos no publicados proporcionados por Ramos. Consideramos que sobre el muro occidental del espacio A -UE 2011- fue levantado un nuevo muro más estrecho-UE 2037-, efectuado con cantos y conglomerados, del que solamente se conserva

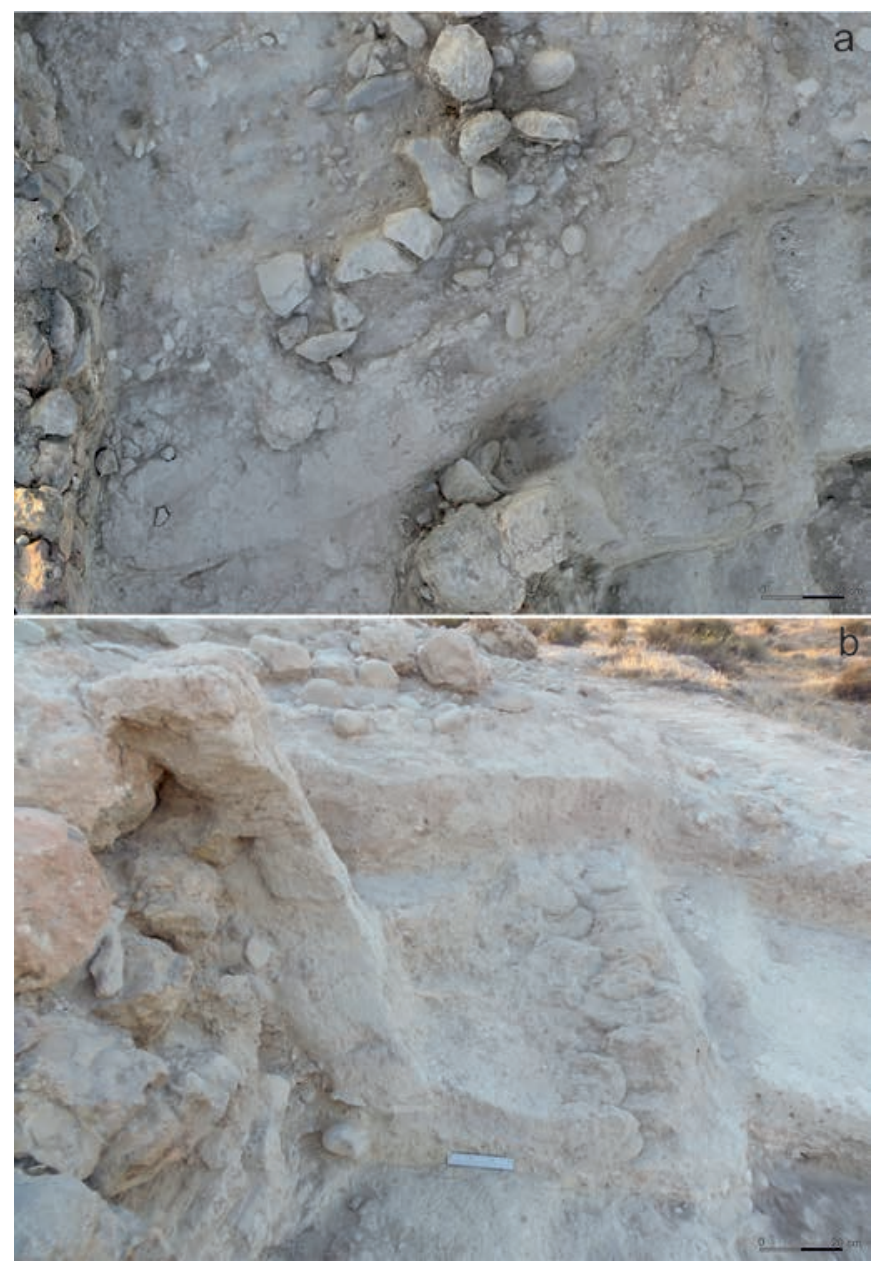

Figura 16. a) Vista cenital de la zona de contacto entre la plataforma UE 2006 y el antemural 2001. Véase el detalle del revestimiento de tierra -UE 1807- sobre el que se habrían colocado las piezas semiesféricas. b) Vista frontal del antemural 2000, su revestimiento y la estructura de bloques de barro amasados -UE 1806-.

un pequeño tramo. No podemos asegurar que este muro corresponda únicamente al tercero de los momentos de uso descritos, pero dada la documentación en las excavaciones de Ramos de un muro en disposición oblicua al 2037, del que posiblemente arrancaría, el espacio A sería dividido en dos estancias -habitaciones A y B de Ramos-. En la segunda de las estancias también sería construido un nuevo banco, pero ahora adosado al muro occidental.

Pero en este espacio también se construyó un nuevo muro de refuerzo, apoyándose y cubriendo parte de las estructuras y bancos del segundo momento situados en su lado oriental, a la vez que, como resultado de la misma obra, se cerraría el antiguo vano de ingreso en su zona septentrional, abriendo uno nuevo en su extremo más noroccidental (Fig. 17). 


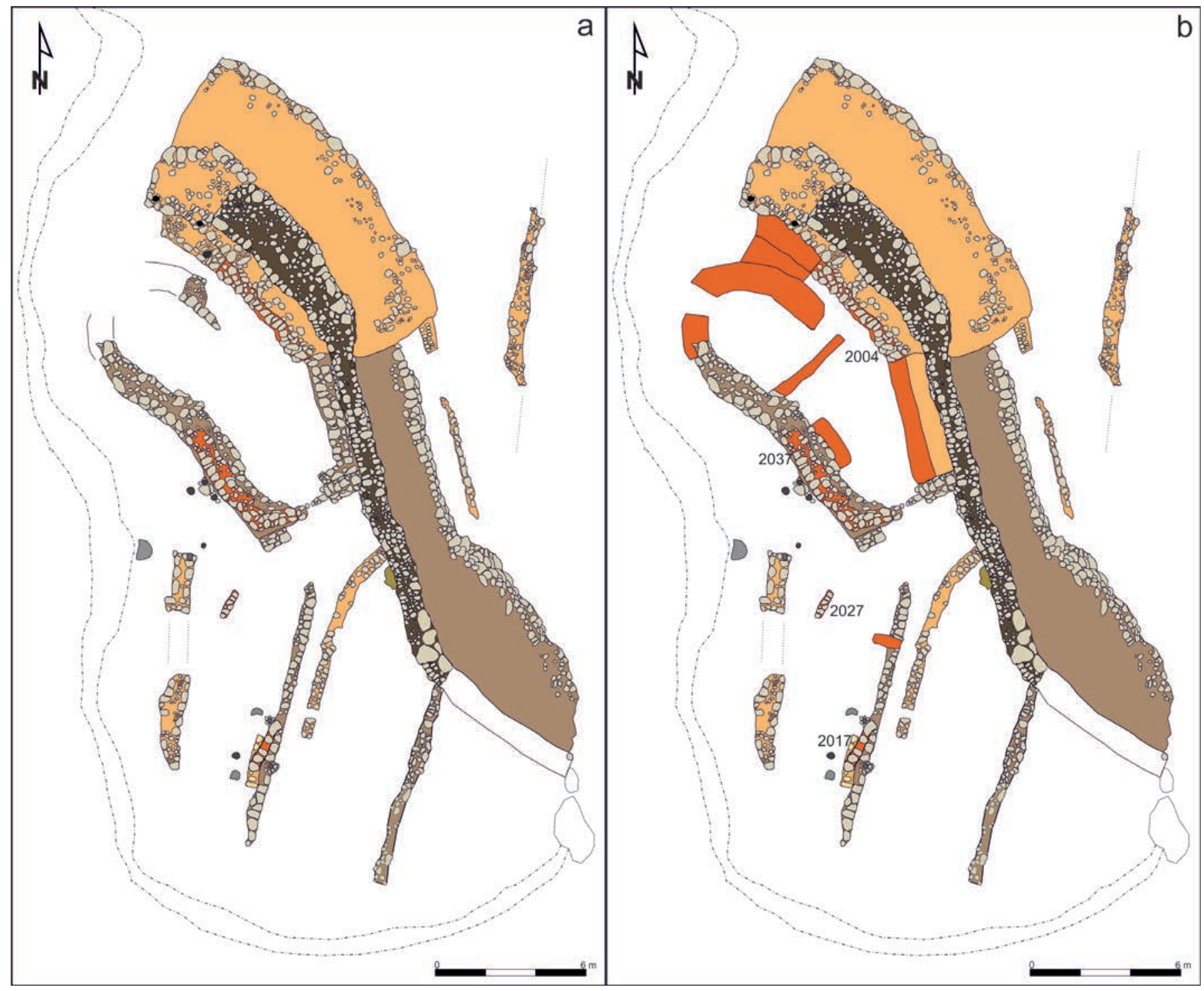

Figura 17. Tercer momento de la secuencia de ocupación de Caramoro I. a) Planta acumulativa de las diferentes estructuras documentadas. En naranja se incluyen las estructuras del tercer momento; b) Planta con la representación de las estructuras del tercer momento, ya desaparecidas.

Por otro lado, la zona del espacio C también sufrió bastantes modificaciones. Sobre los restos del muro 2015 fue acondicionada la zona mediante rellenos sedimentarios de escasa potencia -UUEE 1302, 1303 y 1201 - con el objeto de levantar un nuevo edificio del que solamente se conservan dos pequeños tramos de muros -UUEE 2017 y 2027- con disposición paralela entre ambos con dirección SO-NE, aunque un tercer tramo ya no conservado - levantado en las excavaciones de A. González y E. Ruiz- lo hacía en disposición contraria, pudiendo tratarse de una de las esquinas del edificio. De uno de estos rellenos de acondicionamiento fue seleccionado un fragmento óseo como muestra radiocarbónica. Con su datación pretendíamos determinar si ese resto de basura correspondía al momento de construcción de los tramos de muros de este tercer momento o a basura de los momentos de uso previos. La datación obtenida (Beta-505646: $3630 \pm 30$ BP) permite considerarlo como un desecho del primero de los momentos de uso.

En definitiva, todo parece indicar que los espacios L, E, K, C y D de las ocupaciones anteriores ya no estaban en uso, habiéndose construido nuevos espacios habitacionales en la zona sobre los restos terraplenados o allanados en algunos puntos, de las anteriores ocupaciones. De estos momentos solamente se pudieron registrar las evidencias del abandono de la construcción de la que formaban parte los muros 2027 y 2026 -UE 1503-, del que fue datada una 
muestra (Beta-464793: $3550 \pm 30 \mathrm{BP})$ y el abandono definitivo de la ocupación en la zona D -UUEE 1502 y 1501-, de la que también se realizó una datación (Beta-510335: $3510 \pm 30 \mathrm{BP}$ ).

En definitiva, el proceso de documentación llevado a cabo durante las campañas de 2015 y 2016 ha posibilitado detectar que en Caramoro I se produjeron, a lo largo de su ocupación, diversas reformas y remodelaciones a partir de las construcciones inicialmente edificadas. Estas remodelaciones, en esencia, no cambiaron la estructura del asentamiento, aunque sí lo fortificaron. El resultado de las dataciones obtenidas permite confirmar que el tiempo transcurrido entre la construcción del asentamiento y el último momento de abandono detectado no superó los 250 años. Su ocupación se desarrolló durante el primer cuarto del II milenio cal BC, aunque el balance cronológico radiocarbónico señala el periodo entre 2045 y 1749 cal BC como su posible duración máxima. La posibilidad de haber concretado su ocupación convierte a Caramoro I en un documento excepcional para el estudio del grupo argárico en estas tierras septentrionales.

\section{LAS FORMAS CONSTRUCTIVAS DE CARAMORO I EN EL ÁMBITO DE LA ARQUITECTURA ARGÁRICA}

Caramoro I presenta unos rasgos constructivos que, en general, son compartidos por otros asentamientos argáricos. Aunque en el territorio de El Argar han sido excavados un buen número de asentamientos, sólo de unos pocos han sido analizados sus rasgos arquitectónicos. Entre ellos se encuentran Peñalosa (Baños de la Encina, Jaén) (Contreras 2000, 2009-2010; Moreno 2010), Castellón Alto (Galera, Granada) (Molina et al. 1986; Contreras et al. 1997), Cabezo Pardo (López 2014), La Bastida, Tira del Lienzo (Totana, Murcia) (Lull et al. 2011, 2015a; Delgado-Raack et al. 2015) y La Almoloya (Lull et al. 2015b). El desarrollo de la investigación ha permitido conocer la construcción de asentamientos emplazados principalmente en ladera y en altura, donde son frecuentes las grandes construcciones de piedra, como en el caso aquí presentado, aunque también se conocen enclaves en llano, como Rincón de Almendricos (Lorca, Murcia) (Ayala 1985, 1991) o Los Cipreses (Lorca, Murcia) (Martínez Rodríguez et al. 1999), que no habrían contado con muros de cierre o defensa hechos de mampostería, aunque en el primero de ellos se planteó el hallazgo de los restos de una empalizada de madera (Ayala 1991: 96, fig. 33).

La amplia planificación de los accesos a los asentamientos, la destacada densidad de edificios y su organización a lo largo de pasillos de tránsito, permiten reconocer un urbanismo incipiente para el ámbito de El Argar. No obstante, no ha sido publicados en detalle el desarrollo de la secuencia constructiva y de ocupación de los mismos y en muy pocos casos contamos con trabajos específicos sobre su arquitectura (ver Contreras 2009-2010; Moreno 2010, para el caso de Peñalosa), habiéndose abordado, principalmente, la citada cuestión del urbanismo (Molina y Cámara 2004; Contreras 2009-2010) y las fortificaciones en El Argar (Serrano 2012; Lull et al. 2013, 2014), o las obras hidráulicas (Soler et al. 2004; Lull et al. 2015c). En Caramoro I no se han identificado construcciones que puedan interpretarse como cisternas. No obstante, espacios como el $\mathrm{K}$ y el $\mathrm{G}$ fueron asociados en intervenciones previas a la gestión de agua, concretamente a su evacuación. La existencia de canalizaciones de agua de época argárica se ha planteado en asentamientos como el Cerro de la Virgen (Orce, Granada) (Schüle 1966; Lull 1983: 383; Lull et al. 2015c), o el Rincón de Almendricos (Ayala 2001-2002: 153). De todos modos, la interpretación de un espacio como calle o pasillo no excluye que también hubiera servido para la conducción y drenaje de agua, como se ha planteado, por ejemplo, en La Almoloya (Lull et al. 2015b: 71).

Desde los inicios de El Argar, el uso de la piedra fue fundamental en grandes obras de infraestructura (Lull et al. 2014), así como en la construcción de viviendas y estructuras de actividad, en combinación con otros materiales. La piedra es el material constructivo habitual y claramente el más visible en murallas y/o bastiones, como se observa en La Bastida (Lull et al. 2013, 2014, 2015a), Barranco de la Viuda (Medina y Sánchez 2016), Cerro de la Encina (Aranda y Molina 2005) o Peñalosa (Contreras 2000; 2009-2010; entre otros). Como también ocurriría en el asentamiento de Caramoro I, la protección del enclave suele resultar de la combinación entre las características orográficas del emplazamiento y las construcciones artificiales, en las que, de acuerdo con lo que se conoce para estos momentos, generalmente predomina la técnica de la mampostería, pero también se aplicarían otras, como la piedra seca (Ayala 1979-1980: 155; Eiroa 2004: 59), utilizada asimismo fuera del territorio argárico. Si bien en Caramoro I, un enclave situado en las proximidades del cauce del río, 
pero reforzado de forma considerable, la importancia del uso de la piedra en la construcción es indudable, este también reúne evidencias de construcción con tierra únicas, por el momento, para el ámbito de El Argar y que, además, fueron aplicadas en el área de cierre y mayor fortificación del emplazamiento, sobre y junto al bastión $\mathrm{H}$. Se han documentado estructuras de piedra interpretadas como bastiones en otros asentamientos argáricos, como Tira del Lienzo (Delgado-Raack et al. 2015: 46), Cuesta del Negro, Cerro de la Encina o Peñalosa (Contreras 2009-2010: 46). Respecto a la disposición de la piedra mediante el aparejo en espiga, cuya presencia ya hemos indicado en Caramoro I, también está constatada en asentamientos de El Argar, como la Bastida (Ponsac et al. 1947: 48) o el Barranco de la Viuda (Medina y Sánchez 2016: 39).

En algunos yacimientos del territorio argárico se ha señalado el empleo de tipos concretos de litologías. La arenisca en forma de bloques fue la principal materia prima utilizada en la edificación de viviendas, plataformas de aterrazamiento e incluso cisternas, en asentamientos argáricos como Castellón Alto (Galera, Granada) (Contreras 2009-2010: 52), sin olvidar el empleo de arcillas margosas locales en el trabazón y revestimiento de los muros. En otros asentamientos argáricos se utilizan otras rocas, como en Peñalosa (Baños de la Encina, Jaén), donde la pizarra fue empleada en sus construcciones de mampostería, una piedra también utilizada, entre otros tipos, en La Bastida de Totana (Murcia) (Lull et al. 2015a: 75). En el caso de la construcción de la muralla argárica de la Bastida, de piedra trabada con mortero, ha sido planteado que se escogieron, prioritariamente, areniscas procedentes de un área más alejada del emplazamiento de la muralla, en vez de la pizarra y la caliza disponibles en el sitio, a causa de su mayor facilidad para ser transportadas y escuadradas (Lull et al. 2015a: 51). Del mismo modo, se ha interpretado que las piedras utilizadas en las edificaciones de Tira del Lienzo se habrían obtenido de una rambla cercana, dada la gran dureza de la litología de la cima del cerro y la poca resistencia de los yesos que forman su base (Lull et al. 2015a: 168).

$\mathrm{Al}$ igual que en los casos comentados, en Caramoro I las rocas se emplearon como mampuestos en el alzado de los muros y bancos de las diferentes estancias, así como en las partes fortificadas. Se han podido diferenciar tres tipos. En primer lugar, calizas biclásticas arenosas de distintos tamaños, siendo de este material los grandes bloques de más de $1 \mathrm{~m}$ de longitud. Estas mismas calizas fueron empleadas en el Barranco de la Viuda (Lorca, Murcia) (Medina y Sánchez 2016: 41). Este tipo de roca constituye la base sobre la que fue planificada la instalación del asentamiento. Las calizas están acompañadas de bloques de areniscas, también abundantes en la zona, así como de conglomerados de tamaño medio, entre 20 y $50 \mathrm{~cm}$, integrados por cantos calizos mesozoicos cementados en arenas cuya procedencia se encuentra bajo las calizas biclásticas, en la misma columna estratigráfica que configura el espolón rocoso que ocupa Caramoro I (Fig. 18).

Toda esta serie de recursos litológicos, incluyendo los sedimentos empleados en su trabazón y revestimiento, serían obtenidos en el entorno. A lo largo de las márgenes del río Vinalopó, entre las sierras de Tabayá y Borbano, y en un radio inferior a $5 \mathrm{~km}$ de distancia de Caramoro I, se pueden observar una serie de tramos bien escalonados donde destaca la presencia de arcillas y yesos del Triásico, margas arenosas $\mathrm{y}$ areniscas masivas del Burdigaliense superior, a los que les siguen otras del Tortoniense y Andaluciense, y que se completan con los conglomerados señalados. En el techo de esta secuencia se suele encontrar caliza biclástica arenosa con fauna marina (Pignatelli 1973). Entre los factores que influirían a la hora de utilizar un determinado tipo de piedra como material constructivo se encontrarían su dureza y resistencia estructural, su capacidad para resistir la erosión, la facilidad a la hora de extraerla de una cantera, en su caso, y de darle forma, así como su disponibilidad en el entorno, en relación al coste de su transporte (Rapp y Hill 2006: 214). Así, las rocas sedimentarias como las calizas arenosas y los cantos calizos empleados en Caramoro I son generalmente más fáciles de trabajar respecto a otras rocas, como las metamórficas o ígneas y, por ello, serían utilizadas como materiales de construcción (Morriss 2000: 27). Además, su abundancia y variedad de tamaño en el mismo emplazamiento donde se ubica Caramoro I habrían facilitado enormemente su obtención y puesta en obra.

Respecto al uso de la piedra en la construcción de viviendas argáricas, sólo en algunos enclaves, como La Bastida o Peñalosa, se conocen edificaciones en las que los muros se habrían construido con mampostería hasta una importante altura o por completo. Por el contrario, es habitual la construcción, sobre zócalos de piedra, de alzados de tierra, combinada o no con elementos vegetales, siendo construidos con tierra masiva (Guillaud et al. 2007; Knoll et al. e. p.; entre otros) o mediante la 


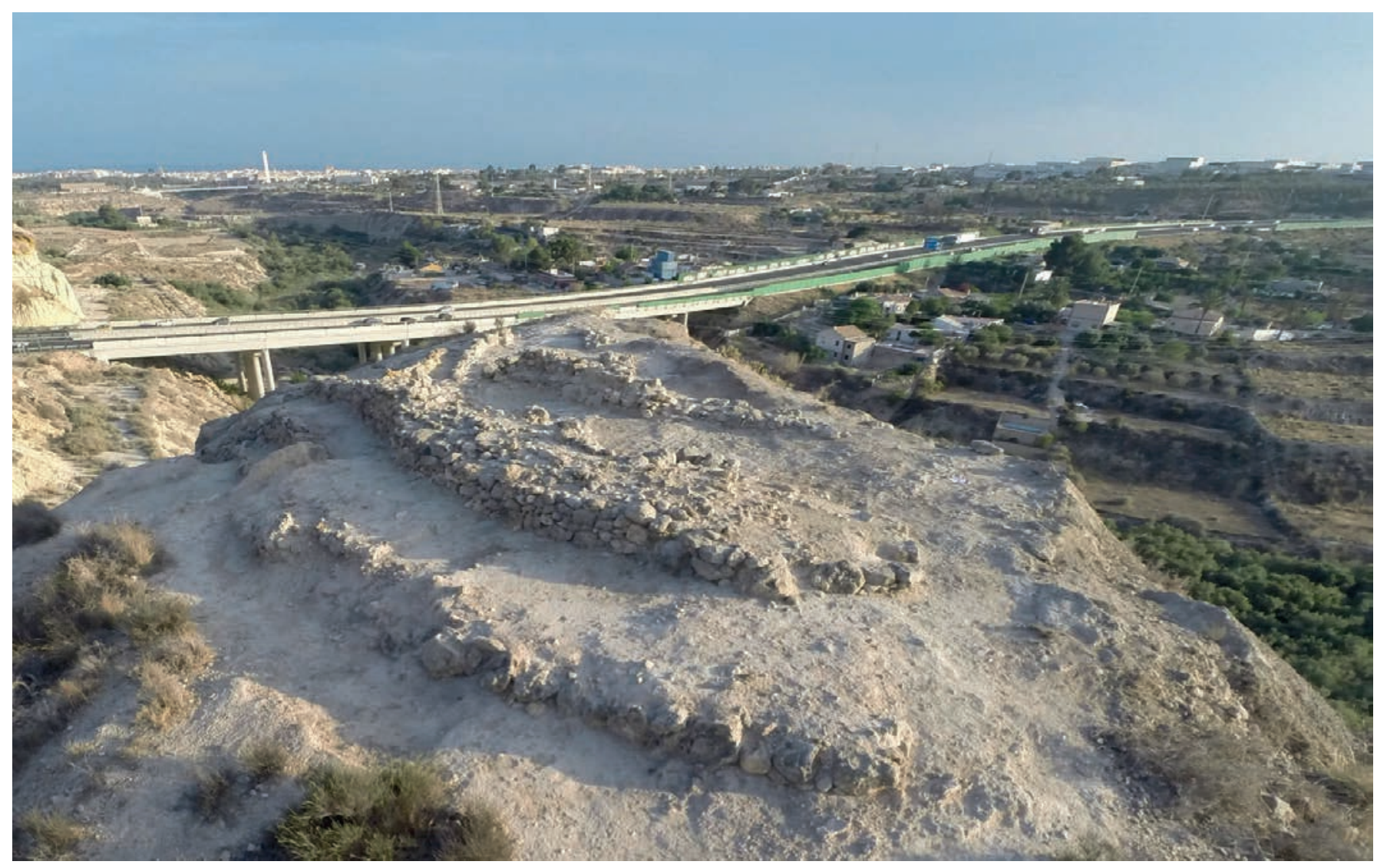

Figura 18. Vista de pájaro desde el noreste de Caramoro I efectuada con un dron. En primer término, el bastión 2006 y la zona de acceso.

técnica del bahareque, de lo que se conocen numerosos ejemplos a lo largo del territorio argárico.

En el caso concreto de Caramoro I se construyeron 11 espacios diferentes. La planta de los mismos es alargada, con una forma más o menos rectangular, formada por muros en su mayoría rectilíneos, aunque construyéndose también algunas formas de tendencia curva. Respecto a las técnicas constructivas detectadas, los alzados habrían sido construidos mediante la técnica de la mampostería de piedra, en su mayoría por completo, aunque no podemos descartar del todo que algunos muros interiores y de menor grosor hubieran contado con parte del alzado construido con otra técnica. El estudio macrovisual de los fragmentos constructivos de barro de Caramoro I ha hecho posible visibilizar el empleo de diferentes técnicas de construcción con tierra (Doat et al. 1979; Knoll y Klamm 2015; Knoll et al. e. p.; entre otros). Entre ellas se han identificado las del amasado, bahareque (Viñuales et al. 2003; Guerrero 2007; Pastor 2017), manteado de barro sobre diferentes especies vegetales y amasado de barro en forma de bolas (Fig. 19) (Pastor et al. 2018), aplicadas junto con la mampostería.
En el estudio macrovisual de los restos constructivos de tierra del asentamiento no se han hallado improntas de troncos, aunque la presencia de postes de madera está constatada mediante la ya citada documentación de sus calzos en casi todos los espacios, además de en el contrafuerte de acceso al asentamiento. En cuanto a la construcción de tabiques internos que dividan las estancias, frecuentes en la arquitectura argárica, únicamente se ha identificado un posible muro medianero, que habría sido construido con tierra y piedras, en el espacio A.

Referencias a los aspectos constructivos de los enclaves argáricos existen desde los inicios de su estudio (Siret y Siret 1890). En la obra de Lull (1983) sobre El Argar, también se abordaba la caracterización de las edificaciones de muchos asentamientos, desde Laderas del Castillo (Callosa de Segura, Alicante) hasta el propio enclave de El Argar (Antas, Almería), en los que se apuntaba el empleo de la técnica del bahareque, asociada principalmente, aunque no exclusivamente, a las cubiertas. La forma que se ha planteado mayoritariamente para las techumbres de las construcciones argáricas es que serían planas o inclinadas a una vertiente, 


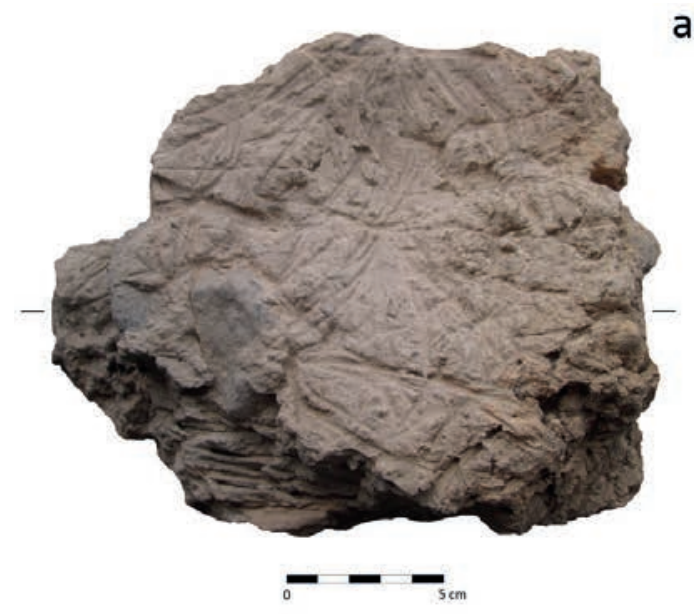

a

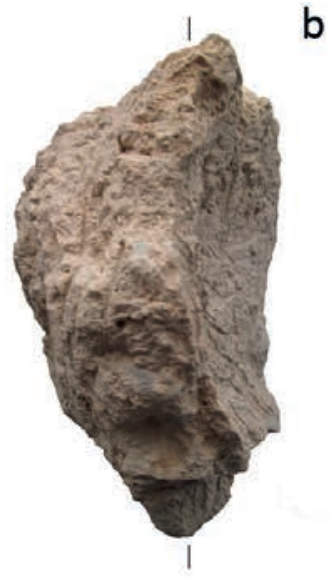

b

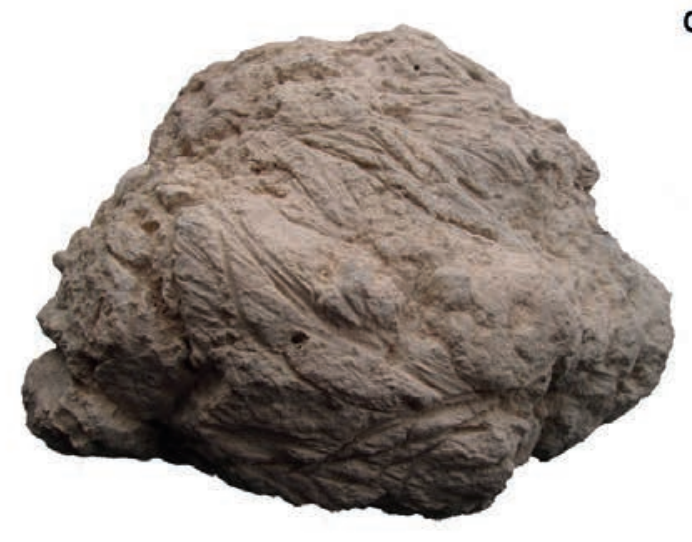

Figura 19. Diferentes vistas de una de las piezas de barro amasado, asociadas al bastión $\mathrm{H}$. a) Cara con rehundimiento central. b) Vista lateral de la pieza, donde se observa dicho rehundimiento. c) Cara contraria y convexa de la misma pieza. Obsérvense las huellas del empleo de vegetales de considerable longitud.

como ya ha sido señalado (Molina y Cámara 2004: 17), algo que también cabe proponer para Caramoro I. Otro rasgo constructivo documentado en Caramoro I son los postes embutidos en los muros, identificados asimismo en Castellón Alto (Contreras et al. 1997), Fuente Álamo (Pingel et al. 2005: 195), Terrera del Reloj (Molina et al. 1986: 354-355, Lám. IIa; Contreras 2009-2010: 54), La Bastida (Totana, Murcia) (Lull et al. 2009: 211), Cerro de las Viñas (Coy, Murcia) (Ayala 1991: 194, 197) o los cercanos asentamientos de Cabezo Pardo (López 2014) y Laderas del Castillo (López et al. 2017).

La madera y la materia vegetal, aunque menos visibles, también fueron materiales constructivos de importancia en labores constructivas. En Caramoro I se han conservado diversos agujeros de poste en el interior del asentamiento que habrían contribuido a sustentar las techumbres, algunos exentos, y otros encastrados en los muros, bancos y contrafuertes. Asimismo, la madera se habría utilizado en largueros y travesaños de las cubiertas, aunque no se han conservado evidencias directas de ello. El estudio de los restos antracológicos recuperados tanto en las excavaciones antiguas, como en las recientes $^{6}$, ha ofrecido una imagen de la vegetación leñosa que habría estado presente en el entorno del enclave, además de apuntar la selección de distintas especies para las actividades constructivas. Se ha observado una presencia significativa de pino, olivo y pistacia, además de tamarindo, conservándose en algunos casos en forma de troncos de gran tamaño y asociados a calzos de poste.

\footnotetext{
${ }^{6}$ Estudio realizado por Mónica Ruíz Alonso.
}

En el entramado de las techumbres se habría utilizado materia vegetal, habiéndose recuperado una decena de restos de barro con improntas de caña y carrizo (Fig. 20) que podrían pertenecer a las cubiertas, así como improntas de hojas alargadas y planas, posiblemente pertenecientes también a estas plantas. También se utilizaron vegetales integrados en los morteros de tierra, a modo de estabilizante y contribuyendo a conformar las bolas y bloques de barro amasado.

Las mismas especies identificadas en Caramoro I se documentan en otros poblados argáricos como Rincón de Almendricos (Ayala et al. 1989: 284), Barranco de la Viuda (Lorca, Murcia) (García Martínez et al. 2011) o Castellón Alto (Contreras 2009-2010: 52), estando también presente en Cabezo Pardo (Carrión 2014). La importante presencia del empleo del pino carrasco en los asentamientos de la Edad del Bronce ha sido resaltada también por diferentes investigaciones antracológicas (Grau 1998; Carrión 2005: 275; Machado et al. 2004, 2009), aunque en el ámbito argárico alicantino, murciano y almeriense parece existir una cierta preferencia por el tamarindo, la olea, e incluso la pistacia. Ejemplos como Cabezo Pardo (Carrión 2014) pero también del cercano yacimiento del Bronce Final de Caramoro II (García Borja et al. 2010), e incluso más meridionales como Fuente Álamo (Carrión 2005) así lo atestiguan. Esta diferenciación entre unas latitudes y otras parece responder, por un lado, a las condiciones más áridas y cálidas de las tierras del sureste en sentido estricto, lo que facilitaría el predominio de especies como el acebuche, el tamarindo, y en las zonas más degradadas, 

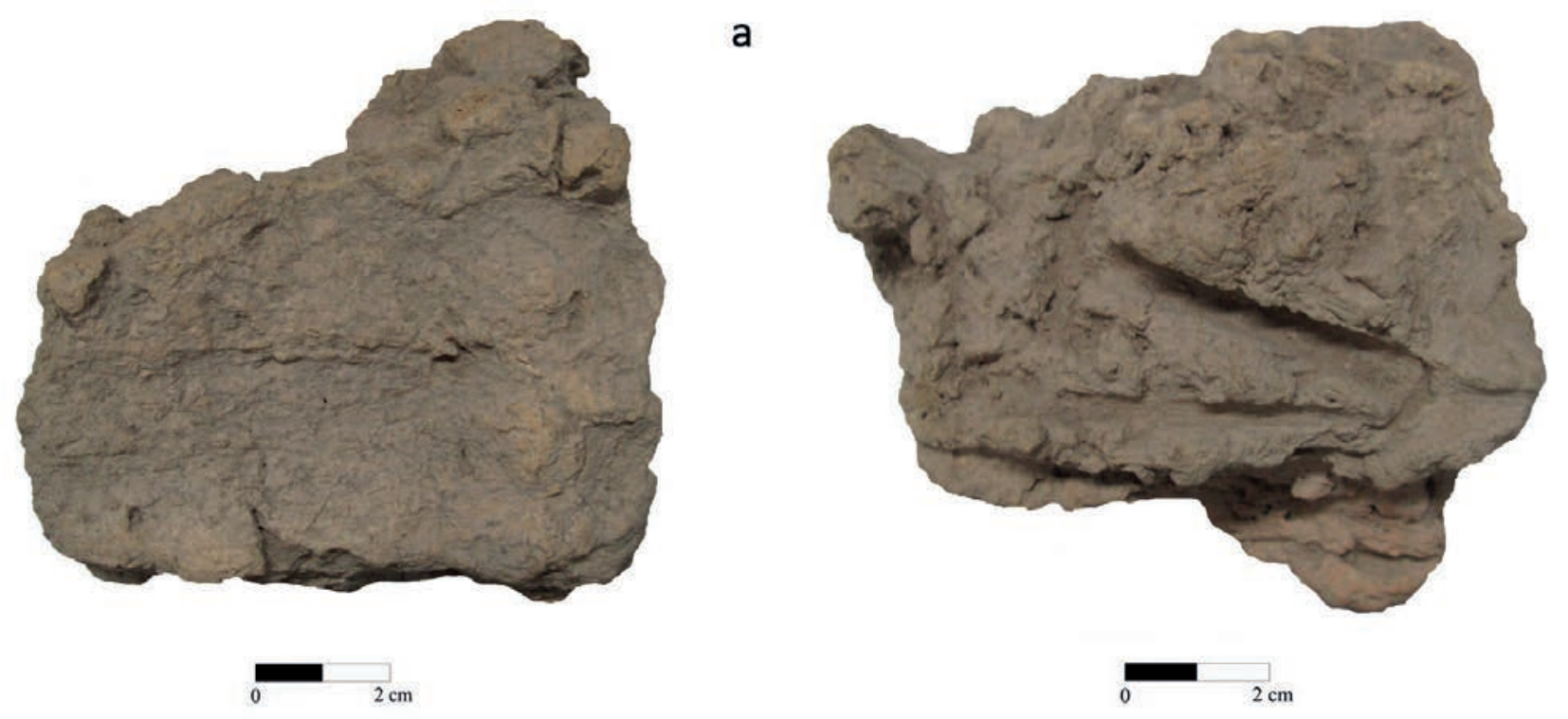

b

Figura 20. Cara externa de un resto constructivo con huellas paralelas de alisado manual, generadas por los dedos de la mano. b. Cara interna con diversas improntas de carrizo.

de la pistacia, frente al pino. Pero también, a un uso preferencial de aquellas especies que, cumpliendo los requerimientos exigidos para su empleo en labores constructivas, se encontraban de forma más extendida en los entornos de los asentamientos. En el caso de Caramoro I, su proximidad a estribaciones montañosas facilitó la selección de pino, pero también de tamarindo, olivo y pistacia. Mientras que en las tierras del Bajo Segura la proximidad de los yacimientos estudiados a zonas encharcadas invirtió los términos, siendo preferente el uso del tamarindo.

Las técnicas constructivas empleadas en los asentamientos argáricos suelen mencionarse y en algunos casos se indica la presencia de restos constructivos de tierra (ya en Siret y Siret 1890). No obstante, no abundan los estudios específicos sobre los materiales y técnicas constructivas empleados en el ámbito de El Argar. En este sentido, entre los trabajos que abordan los materiales constructivos argáricos destacan los de restos de tierra, realizados desde una perspectiva tanto macroscópica como microscópica. Estos análisis han sido abordados para Rincón de Almendricos (Lorca, Murcia) (Ayala y Ortiz 1989; Ayala et al. 1989), Peñalosa (Baños de la Encina, Jaén) (Rivera 2007, 2009, 2011) y Cabezo Pardo (San Isidro/Granja de Rocamora, Alicante) (Pastor 2014, 2017; Martínez Mira et al. 2014).

En el interior de Caramoro I son pocas las evidencias que se han podido conservar de la construcción con tierra, aunque posiblemente habría sido aplicada en un mayor número de partes constructivas de las que ha quedado testimonio arqueológico, como en estructuras de equipamiento interno o externo de las edificaciones, de las que se han conservado sólo algunos restos parciales. En las áreas intramuros, el uso del barro se observa principalmente en el mortero de unión de los mampuestos, en revestimientos y en las pavimentaciones. Se han identificado hogares en el espacio interno de algunas edificaciones, así como bancos ubicados en los espacios $\mathrm{A}, \mathrm{B}$ y $\mathrm{C}$, en los que se habría utilizado tanto la tierra como la piedra.

No obstante, en el recinto exterior se han conservado restos de estructuras de tierra de gran relevancia, ya documentadas en las excavaciones de finales de los años 80 e inicios de los 90, cuyo estudio ha podido ser abordado a raíz de las últimas intervenciones (Pastor et al. 2018). El sedimento cuaternario con cantos existente en el entorno inmediato fue utilizado como relleno de contrafuertes y del antemural. Y arcillas margosas de tonos ocres y verdosos fueron empleadas en el alzado y revestimiento del bastión $\mathrm{H}$ y en un tramo de bloques de barro amasado -UE 1806-. En este conjunto destaca la constatación de la técnica constructiva del amasado en forma de bolas, no sólo a través de la recuperación de sus restos constructivos -habiéndose documentado más de un centenar-, sino también por la conservación de un ejemplo directo de su empleo en el alzado de una estructura (ver Fig. 16b). No conocemos ejemplos en la bibliografía científica que recojan su uso en asentamientos 
argáricos, aunque consideramos que es muy posible que esta forma de construir se hubiera empleado en otros enclaves.

Aunque en Caramoro I no se ha detectado hasta la fecha, en distintos asentamientos del ámbito de El Argar se ha propuesto la presencia de enlucidos de cal o encalados, como en La Bastida, Tira del Lienzo (Lull et al. 2015a: 76, 168) y La Almoloya (Lull et al. 2015b: 75). No obstante, no siempre han sido publicados análisis fisicoquímicos sobre la cuestión, como en Rincón de Almendricos (Ayala et al. 1989: 282; Ayala y Ortiz 1989; Ayala 1991: 76-77) y Cabezo Pardo (San Isidro/Granja de Rocamora, Alicante) (Martínez Mira et al. 2014), habiéndose planteado el posible uso de cal en revestimientos desde el III milenio BC (Jover et al. 2016).

Por último, merece mencionarse que Caramoro I guarda significativas concomitancias con otros asentamientos bastante alejados, como Piedras Bermejas (Baños de la Encina, Jaén) (Contreras et al. 1993), localizados en el extremo noroccidental del territorio argárico, en la cuenca del Rumblar. Este emplazamiento, definido como un asentamiento estratégico tipo fortín, es conocido por las actuaciones llevadas a cabo para su documentación planimétrica y topográfica. Se caracteriza por su reducido tamaño -ocupando una superficie de 750 $\mathrm{m}^{2}-$, la existencia de un recinto de planta piriforme con unas dimensiones máximas de $32 \mathrm{~m}$ de longitud por 22 $\mathrm{m}$ de anchura, y la presencia de potentes muros con un grosor que oscila entre 1,60 y $2 \mathrm{~m}$. En él se distinguen dos espacios diferentes, una torre de tendencia circular en el ángulo sureste para reforzar la entrada -similar a las documentadas en Peñalosa (Fig. 21)-, con una envergadura de los muros superior a los $2 \mathrm{~m}$, y un recinto oval amurallado en el que abren dos accesos opuestos, situados en las zonas noroeste y sur, ya que son las zonas que permiten un acceso de menor dificultad. En un segundo momento, se produjo una reestructuración de estos accesos, adosando nuevos tramos adaptados al trazado de la estructura original y estrechando con ello las puertas de acceso. Finalmente, se produjo el definitivo cierre de la puerta sur y un reforzamiento general con adosamientos sucesivos de lienzos en todo este flanco, dejando sólo el acceso desde el noroeste (Contreras et al. 1993). Procesos similares de refuerzo de los accesos han sido documentados en Caramoro I. La protección y la limitación del acceso al interior del asentamiento fue una de las grandes preocupaciones de sus constructores durante el periodo en el que estuvo ocupado.

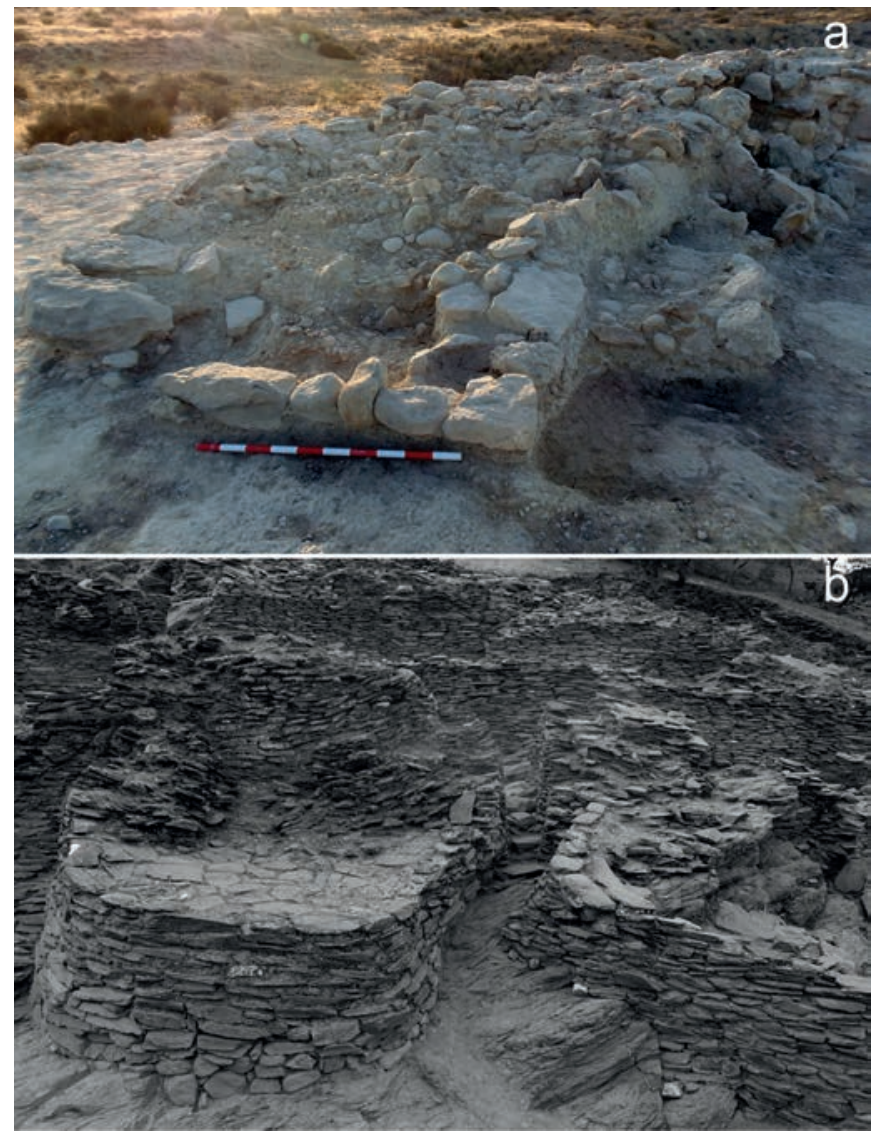

Figura 21. a) Vista del contrafuerte UE 2002 y del banco, en el acceso a Caramoro I. b) Acceso norte de Peñalosa (Contreras 2009-2010, p. 61, Lám. 14).

\section{CONCLUSIONES}

Caramoro I es un asentamiento argárico excavado durante las décadas de 1980 y 1990 con objetivos de investigación muy diversos. Lamentablemente, la publicación parcial de los resultados de estas intervenciones (Ramos 1988; González y Ruiz 1995), provocó que este enclave fuera un gran desconocido, tanto a nivel científico como social. Los trabajos emprendidos recientemente han posibilitado la obtención de información de mejor calidad, siendo el único asentamiento de pequeñas dimensiones que se había excavado en los confines orientales de El Argar (Jover y López 1997, 2009).

A pesar de las limitaciones impuestas por la ausencia de referencias estratigráficas procedentes de las intervenciones previas realizadas en el yacimiento, la reinterpretación del mismo a partir de la lectura estratigráfica de sus estructuras, apoyada en una serie de dataciones absolutas, ha permitido caracterizar su 
desarrollo constructivo y planificación urbanística. El rasgo más destacable, en este sentido, ha sido poder confirmar una gran inversión laboral que fue efectuada en su inicial construcción, posterior fortificación y protección de su acceso, a pesar de tratarse de un asentamiento de muy pequeño tamaño donde las actividades fundamentales estuvieron orientadas a la producción agropecuaria. Por esta razón, más que calificarlo como torre vigía (Ramos 1988) o fortín (González y Ruiz 1995), deberíamos considerarlo como un pequeño asentamiento de carácter agropecuario fortificado o granja fortificada.

En este sentido, aunque la planificación interior, caracterizada por un edificio principal y otros adyacentes, no difiere de otros núcleos argáricos un poco mayores también dedicados a actividades agropecuarias, caso de Cabezo Pardo (López 2014) o la Tira del Lienzo (Lull et al. 2015a), la arquitectura defensiva no tiene parangón, y no parece haber estado presente en los núcleos citados.

Aunque el modelo de compleja articulación económica observado en la Vega Baja del Segura (López y Jover 2014) es precisamente el mismo que se ha propuesto para el valle del Guadalentín (Delgado-Raack 2008), la organización territorial del Bajo Vinalopó guarda similitudes con el patrón de asentamiento propuesto en los análisis más recientes para el valle del Rumblar (Cámara et al. 2007). En este territorio que, al igual que el que aquí estudiamos, constituye otro de los confines de El Argar, se ha sugerido la existencia de diferencias entre los asentamientos en cuanto a su capacidad estratégica, así como la presencia de enclaves de muy pequeño tamaño caracterizados como fortines. Estos últimos se distribuyen desde los bordes de la Depresión Linares-Bailén hasta el interior de la cuenca del Rumblar, habiéndose constatado también asentamientos de mayores dimensiones, aunque dentro de una articulación territorial en la que estarían controlados por los núcleos centrales de la Depresión y de la Loma de Úbeda, donde la jerarquización social se muestra de forma más clara en los enterramientos (Zafra 1991; Zafra y Pérez 1992; Lizcano et al. 2009).

Por tanto, la función que pudo cumplir Caramoro I entre el 2000 y el 1750 cal BC en los límites septentrionales de El Argar debe ponerse en relación con su ubicación en una de las vías principales de entrada y salida al espacio social argárico, lo que explicaría su especial configuración y arquitectura.

\section{AGRADECIMIENTOS}

Agradecemos a Alfredo González Prats y Elisa Ruiz Segura el proporcionarnos la planimetría efectuada durante sus excavaciones en el yacimiento, así como acceso a la copia del diario de excavación y documentación fotográfica. También a Ana M. Álvarez Fortes, codirectora de los trabajos en Caramoro I en 2015 y 2016 y técnica del Museo Arqueológico y de Historia de Elche, las facilidades prestadas en el acceso y consulta de los fondos materiales y documentales. Y a Mónica Ruiz Alonso, investigadora del CSIC, los datos utilizados procedentes de un estudio en proceso de publicación.

\section{BIBLIOGRAFÍA}

Aranda Jiménez, G. y Molina González, F. 2005: “Intervenciones arqueológicas en el yacimiento de la Edad del Bronce del Cerro de la Encina (Monachil, Granada)", Trabajos de Prehistoria 62, 1, pp. 165-80. https:// doi.org/10.3989/tp.2005.v62.i1.61

Aranda Jiménez, G., Montón-Subías, S. y Sánchez Romero, M. 2015: The Archaeology of Bronze Age Iberia. Argaric Societies. Routledge Studies in Archaeology 17. New York and London: Routledge.

Ayala Juan, M. M. 1979-1980: "La Cultura del Argar en la Provincia de Murcia”, Anales de Prehistoria, 38, 4, pp. 147-192.

Ayala Juan M. M. 1985: El poblado argárico del Rincón, Almendricos (Lorca, Murcia)", XVII CNA (Logroño, 1983), pp. 291-297.

Ayala Juan, M. M. 1991: El poblamiento argárico en Lorca. Estado de la cuestión. Ed. Real Academia Alfonso X El Sabio, C. A M. y Ayuntamiento de Lorca.

Ayala Juan, M. M. 2001-2002: "La Edad de Bronce en la región de Murcia", en Hernández Pérez, M. S. (ed.), ...Y acumularon tesoros. Mil años de historia en nuestras tierras, pp. 151-161. Alicante.

Ayala Juan, M. M. y Ortiz González, R. 1989: “Análisis por difracción de rayos $\mathrm{X}$ de enlucidos de las casas argáricas de los yacimientos el Rincón de Almendricos y el Cerro de las Viñas de Coy, Lorca", Crónica del XIX Congreso Arqueológico Nacional (Castellón, 1987), 1, Universidad de Zaragoza, Zaragoza, pp. 323-328.

Ayala Juan, M. M., Rivera Núñez, D. y Obón De Castro, C. 1989: "Improntas vegetales de adobes procedentes de la casa A del yacimiento argárico en llanura de Rincón de Almendricos, Lorca, Murcia”, en Crónica del XIX Congreso Arqueológico Nacional (Castellón, 1987), 1, pp. 279-291. Universidad de Zaragoza, Zaragoza.

Cámara Serrano, J. A., Contreras Cortés, F.; Lizcano Prestel, R., Pérez Bareas, C., Salas Herrera, J. E., Spanedda L. 2007: "Patrón de asentamiento y control de los recursos en el valle del Rumblar durante la Prehistoria Reciente", en Morín, J., Urbina, D. y Bicho, N. F. (eds.), As Idades do Bronze e do Ferro na Península Ibérica: Actas IV Congresso de Arqueologia Peninsular (Faro, 2004), 9, pp. 273-287. Promontoria Monográfica, Faro.

Carrión Marco, Y. 2005: La vegetación mediterránea y atlántica de la Península Ibérica. Nuevas secuencias antracológicas, Trabajos Varios del Servicio de Investigación Prehistórica 104. Diputación Provincial de Valencia, Valencia.

Carrión Marco, Y. 2014: “Cabezo Pardo. La vegetación leñosa y su explotación en el asentamiento argárico", en López Padilla, J. A. (coord.), Cabezo Pardo (San Isidro/ Granja de Rocamora, Alicante). Excavaciones arqueológicas en el yacimiento de la Edad del Bronce, MARQ Memorias Excavaciones Arqueológicas 6, pp. 307-314. Diputación de Alicante, Alicante. Cloquell, B. y Aguilar, M. 1996: "Herida por espada en un niño argárico", Revista de Arqueología, 184, pp. 10-15. 
Contreras Cortés, F. (coord.) 2000: Proyecto Peñalosa. Análisis histórico de las comunidades de la Edad del Bronce del piedemonte meridional de Sierra Morena y depresión Linares- Bailén. Junta de Andalucía, Consejería de Cultura, Sevilla.

Contreras Cortés, F. 2009-2010: “Los grupos argáricos de la Alta Andalucía: patrones de asentamiento y urbanismo. El poblado de Peñalosa (Baños de la Encina, Jaén)", Anales de Arqueología y Prehistoria de la Universidad de Murcia, 25-26, pp. 49-76.

Contreras Cortés, F., Rodríguez-Ariza, M. O., Cámara Serrano, J. A. y Moreno, A. 1997: Hace 4000 años... Vida y muerte en dos poblados de la Alta Andalucía. Catálogo de la exposición. Junta de Andalucía, Fundación Caja de Granada, Granada.

Contreras Cortés, F., Sánchez Ruiz, M., Cámara Serrano, J. A., Gómez Del Toro, E., Lizcano Prestel, R., Moreno Onorato, A., Moya García, S., Nocete Calvo, F., Pérez Bareas, C., Pregigueiro Sánchez, R. y Sánchez Susí, R. 1993: "Análisis histórico de las comunidades de la Edad del Bronce en la Depresión Linares-Bailén y estribaciones meridionales de Sierra Morena. Actuaciones en 1991", Anuario Arqueológico de Andalucía 1991, II, pp. 289-294.

Delgado-Raack, S. 2008: Prácticas económicas y gestión social de recursos (macro)líticos en la prehistoria reciente (III-I milenios a.C.) del Mediterráneo occidental. Tesis doctoral, Universidad Autónoma de Barcelona.

Delgado-Raack, S., Lull Santiago, V., Martin, K., Micó Pérez, R., Rihuete Herrada, C. y Risch, R. 2015: "Espacios de forja en El Argar. El edificio central de Tira del Lienzo (Totana, Murcia)", MARQ, arqueología y museos, 6, pp. 45-64.

Doat, P., Hays, A., Houben, H., Matuk, S. y Vitoux, F. 1979: Construire en terre. CRAterre- Éditions Alternatives, Paris.

Eiroa García, J. J. 2004: La Edad del Bronce en Murcia, Ed. Real Academia Alfonso X el Sabio, Murcia.

García Borja, P., Carrión Marco, Y., Collado Beneyto, I., Montero Ruiz, I., Muñoz Abril, M., Pérez Jordá, G., Roldán García, C., Román Monroig, D., Tormo Cuñat, C., Verdasco Cebrián, C. y Vives-Ferrándiz, J. 2010: "Campaña de excavación arqueológica de urgencia en Caramoro II (Elx, Alacant), MARQ, Arqueología y Museos, 4, pp. 37-66.

García Martínez, M. S., Medina Ruiz, A. J. y Gallego Cambronero, D. 2011: "Leña y madera de construcción en el poblado argárico de Barranco de la Viuda (Lorca, Murcia)", Zephyrus, LXVII, pp. 129-143.

González Prats, A. y Ruiz Segura, E. 1995: "Urbanismo defensivo de la Edad del Bronce en el Bajo Vinalopó. La fortificación argárica de Caramoro I (Elche, Alicante)", Estudios de vida urbana, pp. 85-105, Real Academia Alfonso X El Sabio, Murcia.

Grau Almero, E. 1998: "Antracoanálisis de los restos de madera carbonizada del yacimiento", en De Pedro Michó, M. J. (ed.), La Lloma de Betxí, (Paterna, Valencia). Un poblado de la Edad del Bronce, Trabajos varios del Servicio de Investigación Prehistórica 9. Diputación Provincial deValencia, Valencia.

Guerrero Baca, L. F. 2007: “Arquitectura en tierra. Hacia la recuperación de una cultura constructiva", Apuntes, 20, 2, pp. 182-201.

Guillaud, H., De Chazelles, C. A. y Klein, A. (eds.) 2007: Les constructions en terre massive: pisé et bauge. Deuxièmes échanges transdisciplinaires sur les constructions en terre crue, Actes de la table ronde de Villefontaine (Isère), 28-29 mai 2005. Éditions de 1'Esperou, Montpellier.

Jover Maestre, F. J. y López Padilla, J. A. 1997: Arqueología de la muerte. Prácticas funerarias en los límites de El Argar. Universidad de Alicante, Alicante.

Jover Maestre, F. J. y López Padilla, J. A. 2009: "Más allá de los confines del Argar. Los inicios de la Edad del Bronce y la delimitación de las áreas culturales en el cuadrante suroriental de la Península Ibérica, 60 años después”, en Hernández Pérez, M. S., Soler Díaz, J. A. y López Padilla, J. A. (eds.), En los confines del Argar. Una cultura de la Edad del Bronce en Alicante, pp. 268-291, Fundación MARQ, Diputación de Alicante, Alicante.

Jover Maestre, F. J., Martínez Monleón, S., De Miguel Ibáñez, M-P., López Padilla, J. A., Torregrosa Giménez, P., Pastor Quiles, M. y Basso Rial, R. 2018: “¿Violencia física o accidente? Nuevos datos sobre el enterramiento infantil de Caramoro I (Elche, Alicante, España)", Arqueología Iberoamericana, 38, pp. 25-31.

Jover Maestre, F. J., Pastor Quiles, M., Martínez Mira, I. y Vilaplana Ortego, E. 2016: "El uso de la cal en la construcción durante la Prehistoria reciente en el Levante de la península ibérica: nuevas aportaciones para su identificación", Arqueología de la Arquitectura, 13, pp. 1-18.

Knoll, F. y Klamm, M. 2015. Baustoff Lehm - seit Jahrtausenden bewährt. Archäologische, historische und rezente Zeugnisse des Lehmbaus. Ein Leitfaden für den Umgang mit "Rot- oder Hüttenlehm” im archäologischen Befund, Kleine Hefte zur Archäologie in Sachsen-Anhalt 12. Landesamt für Denkmalpflege und Archäologie Sachsen-Anhalt, Halle.

Knoll, F., Pastor Quiles, M., De Chazelles. C. A. y Cooke, L. en prensa: On cob balls, adobe and daubed straw plaits: A glossary on traditional earth building techniques (walls) in four languages. Tagungen des Landesmuseum für Vorgeschichte Halle, Band 18. Landesamt für Denkmalpflege und Archäologie Sachsen-Anhalt, Halle.

Lizcano Prestel, R., Nocete Calvo, F. y Péramo de la Corte, A. 2009: Las Eras. Proyecto de puesta en valor y uso social del Patrimonio Arqueológico de Úbeda (Jaén). Huelva.

López Padilla, J. A. (coord.) 2014: Cabezo Pardo (San Isidro/Granja de Rocamora). Excavaciones arqueológicas en el yacimiento de la Edad del Bronce. MARQ Memorias Excavaciones Arqueológicas 6, Alicante.

López Padilla, J. A. y Jover Maestre, F. J. 2014: “Cabezo Pardo. Una aldea de campesinos en el confín de El Argar”, en López Padilla, J. A. (coord.), Cabezo Pardo (San Isidro/Granja de Rocamora, Alicante). Excavaciones arqueológicas en el yacimiento de la Edad del Bronce, MARQ Memorias Excavaciones Arqueológicas 6, pp. 395-409. Diputación de Alicante, Alicante.

López Padilla, J. A., Jover Maestre, F. J., Martínez Monleón, S., Sánchez Lardiés, A., Luján Navas, A., Pastor Quiles, M. y Basso Rial, R. 2017: "El Argar alicantino. La Edad del Bronce en el Bajo Segura y Bajo Vinalopó”, en Tomad y bebed. Una copa para un ritual milenario, MARQ, pp. 65-85. Diputación de Alicante, Alicante.

Lull Santiago, V. 1983: La Cultura del Argar. Un modelo para el estudio de las formaciones económico-sociales prehistóricas. Akal, Madrid.

Lull Santiago, V., Micó Pérez, R., Rihuete Herrada, C. y Risch, R. 2009: "El yacimiento arqueológico de La Bastida (Totana): pasado y presente de las investigaciones", Cuadernos de La Santa, 11, pp. 205-217.

Lull Santiago, V., Micó Pérez, R., Rihuete Herrada, C. y Risch, R. 2011: "Proyecto La Bastida: economía, urbanismo y territorio de una capital argárica", Verdolay, 13, pp. 57-70.

Lull Santiago, V., Micó Pérez, R., Rihuete Herrada, C. y Risch, R. 2013: "La fortificación de La Bastida y los orígenes de la violencia militarizada en Europa", Cuadernos de La Santa, 15, pp. 247-254.

Lull Santiago, V., Micó Pérez, R., Rihuete Herrada, C. y Risch, R. 2014: "La Bastida fortification system: new light and new questions on the Early Bronze Age societies in the Western Mediterranean", Antiquity, 88, 340, pp. 395-410. https://doi.org/10.1017/S0003598X00101073

Lull Santiago, V., Micó Pérez, R., Rihuete Herrada, C. y Risch, R. 2015a: La Bastida y la Tira del Lienzo (Totana, Murcia). Ruta argárica, Guías arqueológicas 1. Integral, Sociedad para el Desarrollo Rural, ASOMEUAB. Murcia.

Lull Santiago, V., Micó Pérez, R., Rihuete Herrada, C., Risch, R., Celdrán Beltrán, E., Fregeiro Morador, M. I., Oliart Caravatti, C. y Velasco Felipe, C. 2015b: La Almoloya (Pliego, Murcia). Ruta Argárica, Guías Arqueológicas 2. Integral, Sociedad para el Desarrollo Rural, ASOME-UAB. Murcia

Lull Santiago, V., Micó Pérez, R., Rihuete Herrada, C. y Risch, R. 2015c: "La gestión del agua durante El Argar: el caso de La Bastida (Totana, Murcia)", Minius, 23, pp. 91-130.

Machado Yanes, M. C., Jover Maestre, F. J. y López Padilla, J. A. 2004: "Primeras aportaciones antracológicas del yacimiento de Terlinques (Villena, Alicante)", en Hernández Alcaraz, L. y Hernández Pérez, M. S. (eds.), La Edad del Bronce en tierras valencianas y zonas limitrofes, pp. 363-368. Institut de Cultura "Juan Gil-Albert", Alicante.

Machado Yanes, M. C., Jover Maestre, F. J. y López Padilla, J. A. 2009: “Antracología y paleoecología en el cuadrante suroriental de la península 
Ibérica: las aportaciones del yacimiento de la Edad del Bronce de Terlinques (Villena, Alicante)", Trabajos de Prehistoria, 66, 1, pp. 75-96. https:// doi.org/10.3989/tp.2009.09013

Martínez Mira, I., Vilaplana Ortego, E., Such Basáñez, I., Juan Juan, J. y García Del Cura, M. A. 2014: "Cabezo Pardo. Análisis instrumental de materiales de construcción de barro del yacimiento argárico", en López Padilla, J. A. (coord.), Cabezo Pardo (San Isidro/Granja de Rocamora). Excavaciones arqueológicas en el yacimiento de la Edad del Bronce, MARQ Memorias Excavaciones Arqueológicas 6, pp. 330-378. Alicante.

Martínez Monleón, S. 2014. El Argar en el Bajo Segura y Bajo Vinalopó: patrón de asentamiento en un territorio de frontera. Fundación José María Soler, Villena.

Martínez Rodríguez, A., Ponce García, J. y Ayala Juan, M. M. 1999: “Excavaciones de urgencia del poblado argárico de Los Cipreses, Lorca. Años 1992-93”, Memorias de Arqueología, 8, pp. 155-182.

Medina Ruiz, A. J. y Sánchez González, M. J. 2016: "El Barranco de la Viuda (Lorca, Murcia), un poblado argárico en el valle del Guadalentín. Excavación arqueológica de 1998-1999", Alberca 14, pp. 31-52.

Molina González, F., Aguayo de Hoyos, P., Fresneda Padilla, E. y Contreras Cortés, F. 1986: "Nuevas investigaciones en yacimientos de la Edad del Bronce en Granada", Homenaje a Luis Siret (1934-1984), pp. 353-360. Consejería de Cultura, Sevilla.

Molina González, F. y Cámara Serrano J. A. 2004: "Urbanismo y fortificaciones en La Cultura de El Argar. Homogeneidad y patrones regionales", en García Huerta, M. R. y Morales Hervás, J. (coords.), La Península Ibérica en el II Milenio A. C. Poblados y fortificaciones, Colección Humanidades, 77, pp. 9.56. Ediciones Universidad Castilla-La Mancha, Cuenca.

Moreno Onorato, A. 2010: “Aprendiendo a construir un poblado argárico. Trabajos de consolidación en Peñalosa (Baños de la Encina, Jaén)", Cuadernos de Prehistoria y Arqueología de Granada, 20, pp. 435-478.

Morriss, R. K. 2000: The archaeology of buildings. Tempus, Stroud.

Pastor Quiles, M. 2014: "Cabezo Pardo. Contribución a las formas constructivas de un hábitat argárico a partir del estudio de los elementos de barro", en López Padilla, J. A. (coord.), Cabezo Pardo (San Isidro/ Granja de Rocamora, Alicante). Excavaciones arqueológicas en el yacimiento de la Edad del Bronce, MARQ Memorias Excavaciones Arqueológicas 6, pp. 306-321. Diputación de Alicante, Alicante.

Pastor Quiles, M. 2017: La construcción con tierra en arqueología: teoría, método, técnicas y aplicación. Servicio de Publicaciones de la Universidad de Alicante, Alicante.

Pastor Quiles, M., Jover Maestre, F. J., Martínez Monleón, S. y López Padilla, J. A 2018: "La construcción mediante amasado de barro en forma de bolas de Caramoro I (Elche, Alicante): Identificación de una nueva técnica constructiva con tierra en un asentamiento argárico", Cuadernos de Prehistoria y Arqueología, 44, pp. 81-99. http://dx.doi.org/10.15366/ cupauam2018.44.004

Pingel, V., Schubart, H., Arteaga Matute, O., Roos, A. M. y Kunst, M. 2005: "Excavaciones arqueológicas en la ladera sur de Fuente Álamo: campaña de 1999”, SPAL, 12, pp. 179-229. http://dx.doi.org/10.12795/spal.2003.i12.08

Pignatelli, R. 1973: Elche. Mapa geológico de España. E. 1:50.000. Segunda serie. Primera edición. IGME. Madrid.
Ponsac Mon, F.; Sopranis Salto, A. y del Val Caturla, E. 1947: "La ciudad y su arquitectura”, en Martínez-Santaolalla, J., Sáez Martín, B., Ponsac Mon, C. F., Sopranis Salto, J.A., Del Val Caturla, E., Excavaciones arqueológicas en la ciudad del Bronce Mediterráneo II, de la Bastida de Totana (Murcia), Informes y Memorias, 16. Comisaría General de Excavaciones Arqueológicas, pp. 47-58. Ministerio de Educación Nacional, Madrid.

Ramos Fernández, R. 1988: "Caramoro: una fortaleza vigía de la Edad del Bronce", Homenaje a Samuel de los Santos, pp. 93-107. Excma. Diputación de Albacete, Albacete.

Rapp, G. y Hill, C.L. 2016: Geoarchaeology. The Earth-science approach to archaeological interpretation. Yale University Press, New Haven-London.

Rivera Groennou, J. M. 2007: “Aproximación a las formas constructivas en una comunidad de la Edad del Bronce: El poblado argárico de Peñalosa (Baños de la Encina, Jaén)", Arqueología y territorio, 4, pp. 5-21.

Rivera Groennou, J. M. 2009: "Micromorfología e interpretación arqueológica: aportes desde el estudio de los restos constructivos de un yacimiento argárico en el Alto Guadalquivir, Peñalosa (Baños de la Encina, Jaén)”, Cuadernos de prehistoria y arqueología de la Universidad de Granada, 19, pp. 339-360.

Rivera Groennou, J. M. 2011: "Técnicas constructivas y relaciones sociales en una comunidad argárica del alto Guadalquivir, Peñalosa (Baños de la Encina, Jaén)", en Memorial Luis Siret, I Congreso de Prehistoria de Andalucía, La tutela del patrimonio prehistórico, pp. 599-602. Junta de Andalucía, Consejería de Cultura, Sevilla.

Schiffer, M. B. 1985: "There is a " 'Pompeii premise' in archaeology?", Journal of Archaeological Research, 41, 1, pp. 18-41.

Schüle, W. 1966: "El poblado del bronce antiguo en el Cerro de la Virgen de Orce (Granada) y su acequia de regadío", en IX Congreso Nacional de Arqueología (Valladolid, 1965), pp. 113-126. Secretaría General de los Congresos Arqueológicos Nacionales, Zaragoza.

Serrano Ariza, R. 2012: "Fortificaciones y estado en la cultura argárica", Arqueología y Territorio, 9, pp. 49-72.

Siret, L. y Siret, H. 1890: Las primeras edades del Metal en el sudeste de España. Barcelona.

Soler Díaz, J. A., Pérez Jiménez, R., Ferrer García, C., Belmonte Mas, D. y Vicedo Jover, J. 2004: "La cisterna $\mathrm{n}^{\circ} 1$ del yacimiento de la Illeta dels Banyets (El Campello, Alicante). Resultado de las actuaciones previas a la puesta en valor de una estructura de la Edad del Bronce”, en Hernández Alcaraz, L. y Hernández Pérez, M. S. (eds.), La Edad del Bronce en tierras valencianas y zonas limitrofes, pp. 269-284. Ayuntamiento de Villena, Instituto Alicantino Gil-Albert, Villena.

Viñuales, G. M., Martins Neves, C. M, Flores, M. y Silvio Ríos, L. 2003. Arquitecturas de tierra en Iberoamérica. Programa Iberoamericano de Ciencia y Tecnología para el Desarrollo (CYTED)-Subprograma XIV Tecnología para Viviendas de Interés Social (HABYTED)-Habiterra-Proterra, Salvador.

Zafra de la Torre, N. 1991: "Excavaciones arqueológicas en el Cerro del Alcázar (Baeza, Jaén). Campaña de 1989, Informe previo", Anuario Arqueológico de Andalucía 1989, III, pp. 328-337.

Zafra de la Torre, N. y Pérez Bareas, C. 1992: "Excavaciones arqueológicas en el Cerro del Alcázar (Baeza, Jaén). Campaña de 1990, Informe preliminar", Anuario Arqueológico de Andalucía 1990, III, pp. 294-303. 